\title{
Differential Sputtering Behavior of Pyrolytic Graphite and Carbon-Carbon Composite Under Xenon Bombardment
}

\author{
John D. Williams, ${ }^{\star}$ Mark L. Johnson, ${ }^{\dagger}$ and Desiree D. Williams ${ }^{\ddagger}$ \\ Colorado State University, Fort Collins, 80523
}

\begin{abstract}
A differential sputter yield measurement technique is described, which consists of a quartz crystal monitor that is swept at constant radial distance from a small target region where a high current density yenon ion beam is aimed. This apparatus has been used to characterize the sputtering behavior of various forms of carbon including polycrystalline graphite, pyrolytic graphite, and PVD-infiltrated and pyrolized carbon-carbon composites. Sputter yield data are presented for pyrolytic graphite and carbon-carbon composite over a range of xenon ion energies from $200 \mathrm{eV}$ to $1 \mathrm{keV}$ and angles of incidence from $0^{\circ}$ (normal incidence) to $60^{\circ}$.
\end{abstract}

\section{Introduction}

$S_{\text {puttering is the physical removal of material from a surface through the means of energetic particle }}$ bombardment. In film deposition applications, sputtering can be the mode by which thin film coatings of target material are applied to surfaces to enhance their mechanical, thermal, or optical properties. In the context of space propulsion using ion or plasma thrusters, sputtering is never desired. In essence, it is an erosion phenomenon that limits the lifetime of components used in these thrusters. Although sputtering has been studied for the past 150 years, the sputter yields for many materials (expressed as the number of atoms removed from the surface for every energetic particle that impacts it) have not been fully characterized, especially for heavy particles like xenon ions with moderate to low energies and non-zero incidence angles that are bombarding materials suitable for electric propulsion components such as pyrolytic graphite (PG) and carbon-carbon composites (CC).

As the interest in electric propulsion (EP) builds, it is becoming important for analysts and designers to have sputter yield data for a wide range of incident ion angles and energies in order to accurately gauge thruster life time. Both total sputter yield (atoms/ion) and differential sputter yield (atoms/ion/steradian) are needed. These data are of interest for calculating erosion of spacecraft surfaces and thruster components that can be struck by highenergy ions produced in the beams of these thrusters. Of equal interest is sputtering caused by ions with lower energies (e.g., low energy charge exchange ions that are accelerated into and strike negatively biased surfaces or ions falling from positive plasma potential structures located within ion thruster discharge chambers or plasma thruster insulator channels). Sputter erosion of surfaces at or near cathode potential that face regions of dense plasma can also occur via bombardment from multi-charged ions. These multi-charged ions can obtain energies corresponding to multiples of the anode to cathode potential difference, which can be above the sputtering threshold for most materials.

Sputter yield data are also of interest for calculating back sputter rates onto thruster and vacuum chamber surfaces from beam dumps in vacuum facilities where life tests and flight acceptance tests are performed. Sputter resistant components fabricated from various forms of carbon have been proposed for life critical components like accel and screen grids, keeper electrodes, discharge chamber liners, etc and for vacuum facility beam dumps and wall liners. However, due to the incredibly long life times required of EP systems, even these components may become highly eroded. Long term life tests of new carbon-based components are prohibitively expensive, and their resistance to erosion will need to be evaluated through the use of models (to specify total impinging ion dose, distribution of angular incidence, and ion energy distribution) in combination with high quality sputter yield data.

\footnotetext{
- Assistant Professor, Mechanical Engineering, 1320 Campus Delivery, AIAA Senior Member

${ }^{\dagger}$ Graduate Research Assistant, Mechanical Engineering, 1320 Campus Delivery, AIAA Student Member

‡ Graduate Research Assistant, Mechanical Engineering, 1320 Campus Delivery
} 
The work described in this paper was initiated in response to the need for sputter yield measurements of materials unique to thruster designs with long life time capability- namely pyrolytic graphite (PG) and specialized carbon-carbon composite materials (CC). In this effort we utilized a technique to measure total and differential sputter yields of pyrolytic graphite and carbon-carbon composites subjected to xenon ion bombardment at energies ranging from $200 \mathrm{eV}$ to $1000 \mathrm{eV}$ and for angles of incidence from $0^{\circ}$ to $60^{\circ}$. The heart of the technique was a quartz crystal monitor (QCM) that was swept at constant radial distance from a small target region where a high-currentdensity xenon ion beam was aimed. The QCM measurements allowed calculation of differential sputter yields (the number of atoms sputtered per ion per steradian of solid angle) versus the polar angle of the QCM measured from the target normal direction. Differential sputtering yields were measured over a $180^{\circ}$ arc in a plane that included the ion beam centerline and the normal vector of the target surface. Total sputter yields can be calculated from differential sputter yield data using simple integration procedures and comparisons to total sputter yield calculations were made to sputter yields obtained from the literature wherever possible.

In this paper, we first present a description of our measurement technique. This section is followed by a presentation of data that has been collected on PG and CC targets. In addition to experimental data, curve fit coefficients for differential sputter yields are listed in tabular form. Finally, the measurements on PG and CC are compared to measurements made by other researchers.

\section{Sputter Yield Measurement Technique}

Differential sputter yield testing was performed by first attaching the PG or CC targets to a water-cooled mounting plate in a vacuum system. The vacuum system was then evacuated and baked to ensure the best possible vacuum conditions. No-flow pressures below $1 \times 10^{-6}$ Torr were achieved before sputter testing was initiated. The basic test apparatus, which is shown schematically in Fig. 1, includes an ion source equipped with a well-focused, $2.5-\mathrm{cm}$ diameter ion optics system. The ion beam is directed onto the center of the target surface, which is located $23 \mathrm{~cm}$ downstream of the ion source grids. This target surface, which is large compared to the beam size, can be rotated to change the angle of incidence of the beam $(\beta)$. For this study, incidence angles were varied from $\beta=0^{\circ}$ (normal incidence) to $\beta=60^{\circ}$.

Sputtered material was sensed as a mass accumulation rate by the quartz crystal monitor (QCM), which is also shown in the Fig. 1. The QCM was mounted on an arm that rotated about the same axis as the one used for target rotation. The QCM sensor was swept on an arc that was $17.8 \mathrm{~cm}$ in radius and was oriented so its sensing face remained pointed at the midpoint of the ion beam impact zone as suggested in Fig. 1. Mass accumulation rates were typically measured over the atom ejection angle $(\alpha)$ range from $\alpha=-90^{\circ}$ to $\alpha=+90^{\circ}$ relative to the target surface normal vector in $10^{\circ}$ to $20^{\circ}$ increments. The polar angle range from 0 to +90 is referred to as the front half of the hemisphere located above the target, and the range from -90 to 0 is referred to as the back half. Material sputtered in the forward

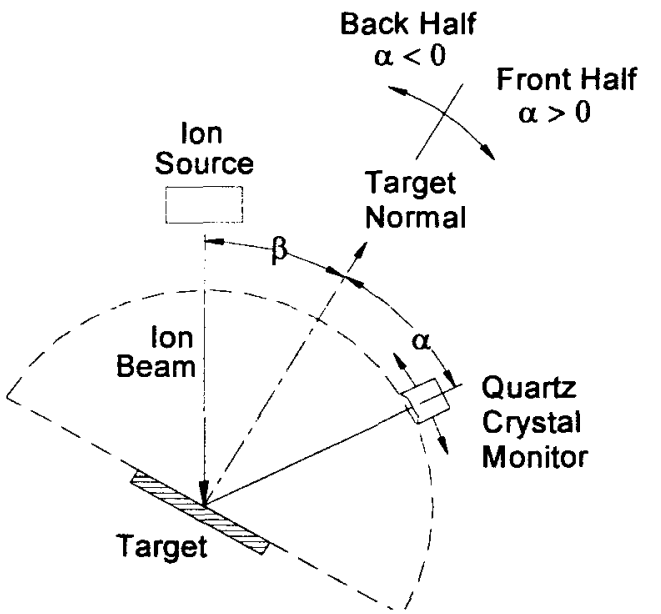

Fig. 1 Sketch of Test Apparatus.

direction (away from the ion beam) is detected in the front half of the hemisphere and material sputtered backward (toward the incident ion beam) is detected in the back half of the hemisphere. It is noted that QCM measurements were not made at positions where the monitor would intercept the ion beam.

QCM data were obtained as changes in mass on the QCM crystal over prescribed intervals of time (several minutes to tens of minutes) at each QCM position. Data collection was repeated as necessary to assure the mass accumulation rate had reached a stable value before final measurements were recorded. During data collection, the total and partial pressures within the vacuum facility were monitored in nitrogen equivalent units using a residual 
gas analyzer (RGA). The total pressure was typically in the low $10^{-5}$ Torr range and xenon was the dominant gas in the chamber at a nitrogen equivalent partial pressure that was very close to the total pressure. Nitrogen (and/or carbon monoxide) was the dominant impurity present during data collection at a partial pressure that was a few percent of the total pressure. Other impurities that were present during data collection were at an order of magnitude lower partial pressure and included oxygen, water vapor, and hydrogen.

One important concern during sputter yield measurements is the need for dynamically clean target surfaces. This is because the presence of background gases adsorbed onto the target surface can mask the true sputter yield behavior of the material. A particularly troublesome background gas that is known to affect sputter yields of metals is nitrogen, and the presence of oxygen ions and excited neutrals can affect sputter yield measurements of carbon and polymer based targets. One can estimate the fraction of the target covered with a background gas using the following equation

$$
\eta_{\mathrm{n}}=\frac{\beta_{\mathrm{n}} \dot{\mathrm{n}}_{\mathrm{n}}}{\mathrm{Y}_{\mathrm{n}} \dot{\mathrm{n}}_{\mathrm{i}}} \leq 0.1
$$

In Eq. (1), $\beta_{n}$ represents the sticking coefficient of a neutral gas atom ( $n$ ), $\dot{n}_{n}$ the rate of arrival of neutral particles to the target surface, $Y_{n}$ the sputter yield of an adsorbed atom, and $\dot{n}_{i}$ the rate of arrival of bombarding ions. As a general rule of thumb, a value of $\eta_{n}$ less than 0.1 will ensure that background gases will not affect sputter yield measurements significantly, and, during our experiments, worst case estimates of the background gas shielding effect $\left(\eta_{n}\right)$ calculated using Eq. (1) were less than 0.05 . Another concern for error in ion beam sputtering measurements is the presence of doubly charged ions in the beam because they have twice the energy of singly charged ions and (if they exist in high numbers) can cause measured sputter yields to be higher than actual yields. We operated the ion source at a flow rate that was three times higher than the rate at which ions were extracted from the ion source. For all of the tests described in this paper, the ion source discharge voltage was set to $30 \mathrm{~V}$. Very few doubly charged ions where expected at this high flow and relatively low discharge voltage, and measurements made with an ExB probe indicated that the doubles-to-singles concentration ratio was less than $2 \%$.

Measurements made at various polar angles $(\alpha)$ using the QCM provide mass accumulation rates $[R(\alpha)]$ in $\mathrm{gm} / \mathrm{sec}$. These can be converted into units of atoms/sec by dividing the mass rates by the molecular mass of the sputtered material $(\mathrm{M}$ in $\mathrm{gm} / \mathrm{mol})$ and multiplying by Avagadro's number $\left(\mathrm{N}_{\mathrm{A}}\right.$ in atoms $\left./ \mathrm{mol}\right)$. These results are converted into fractional sputter yields by dividing by the ion arrival rate, i.e. by the ion current (J) in coul/sec over the ion charge $(q)$ in coul/ion. However, these yields represent only those atoms sputtered onto the QCM sensor through the solid angle subtended by the sensor from the region of beam impact. Because the sensor is swept through a circular arc and its surface always remains normal to the radius vector this solid angle is the same for each measurement. Assuming the ion impact region is small compared to the arc radius, the solid angle is equal to the sensor area $\left(A_{s}\right)$ divided by the square of the arc radius $(r)$. Dividing the fractional sputter yields by the solid angle subtended by the sensor gives angle-dependent differential sputter yields $[y(\alpha)]$. The equation for differential sputter yield in atoms/ion/steradian developed as it has been described above is:

$$
y(\alpha)=\frac{R(\alpha) N_{A} q r^{2}}{M J A_{S}}
$$

Typical differential sputter yield data obtained for $500 \mathrm{eV}$ xenon ions sputtering Poco graphite at a beam current of $11 \mathrm{~mA}$ are shown in Fig. 2 in a polar plot format. The constants needed in Eq. (1) to convert raw rate data $[R(\alpha)]$ into differential yield data for this figure are:

$$
\begin{array}{lll}
N_{A}=6.023 \times 10^{23} \text { atoms } / \mathrm{mol} & \mathrm{q}=1.6 \times 10^{-19} \mathrm{coul} / \mathrm{ion} & \mathrm{r}=17.8 \mathrm{~cm} \\
\mathrm{M}=12 \mathrm{gm} / \mathrm{mol} \text { (carbon) } & \mathrm{J}=11 \times 10^{-3} \mathrm{coul} / \mathrm{sec} & A_{\mathrm{s}}=0.535 \mathrm{~cm}^{2}
\end{array}
$$

The data plotted in Fig. 2 correspond to QCM measurements that were converted using Eq. (2), and the error bars are estimates based on the resolution of the QCM readout and the choice of the sample time. The differential sputter yield profile was observed to be fairly flat with a majority of material sputtered at high polar angles. This same behavior was observed with PG and CC targets and is expected when heavy particles like xenon are directed at targets comprised of light atoms like carbon. The dashed curve shown in Fig. 2 represents a cosine distribution that corresponds to the same total sputter yield as the curve fit to the data. Although the cosine distribution appears to be 
much larger than the measured distribution, the total yield measured in atoms/ion is the same. This is due to geometrical arguments presented below. Cosine distributions are commonly assumed in most wear models of electric propulsion devices. This distribution was included on Fig. 2 to make the point that actual sputtering behavior can be dramatically different than ideal behavior assumed in models where cosine distributions are used. The cosine distributions were calculated from values of total yield given in equations below and the diffuse emission equation given by (Mahan [2000])

$$
y(\alpha)=\frac{Y \cos (\alpha)}{\pi} .
$$

It is possible to obtain the total sputter yield by integrating a function describing the variation in differential yield with $\alpha$ over the full solid angle range through which atoms can be sputtered $(2 \pi$

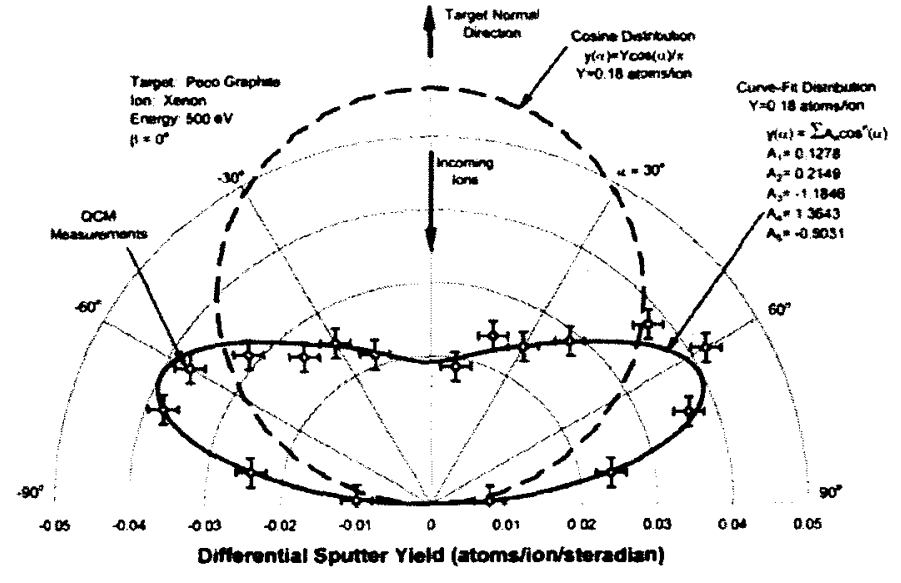

Fig. 2 Typical differential sputter yield data for xenon ions on graphite at normal incidence.

steradians). For the case of normal incidence, where an axi-symmetric distribution is assumed to exist, the differential solid angle is given by

$$
\mathrm{d} \psi=\frac{2 \pi \mathrm{r} \sin (\alpha) \mathrm{rd} \alpha}{\mathrm{r}^{2}}=2 \pi \sin (\alpha) \mathrm{d} \alpha
$$

And the total yield is then given by

$$
\mathrm{Y}=\int_{0}^{\frac{\pi}{2}} 2 \pi \sin (\alpha) \mathrm{y}(\alpha) \mathrm{d} \alpha=\int_{-\frac{\pi}{2}}^{\frac{\pi}{2}} \pi \sin (|\alpha|) \mathrm{y}(\alpha \mid) \mathrm{d} \alpha
$$

For the normal incidence data in this report, the total yield was determined by fitting differential sputter yield data like those plotted in Fig. 2 using up to a fifth-order polynomial and performing the integration analytically.

In order to obtain total yield data for non-normal incidence conditions, it would be necessary to measure differential yields over the entire hemisphere above the target [i.e., obtain $y(\alpha, \phi)$ where $\phi$ is the azimuthal angle] and then integrate the equation:

$$
\mathrm{Y}=\int_{0}^{2 \pi}\left(\int_{0}^{\pi / 2} 2 \pi \sin (\alpha) \mathrm{y}(\alpha, \phi) \mathrm{d} \alpha\right) \mathrm{d} \phi
$$

However, approximate values of the total yields can be obtained from non-normal incidence yield profiles (like the one for $\beta=30^{\circ}$ shown in Fig. 3) using the far RHS form of Eq. (5) and expressions for each half of the hemisphere located above the target surface. This approximation assumes that the variation in the azimuthal direction varies smoothly between values measured in the plane formed by the target normal and the ion beam. If the differential sputter yield data are curve-fit using Eqs. (7) and (8) for the front and back halves of the hemisphere located above the target, respectively, the total yield can be found analytically using Eq. (9). 


$$
\begin{gathered}
\mathrm{y}(\alpha)=\mathrm{A}_{5} \cos ^{5}(\alpha)+\mathrm{A}_{4} \cos ^{4}(\alpha)+\mathrm{A}_{3} \cos ^{3}(\alpha)+\mathrm{A}_{2} \cos ^{2}(\alpha)+\mathrm{A}_{1} \cos (\alpha) \\
\mathrm{y}(\alpha)=\mathrm{B}_{5} \cos ^{5}(\alpha)+\mathrm{B}_{4} \cos ^{4}(\alpha)+\mathrm{B}_{3} \cos ^{3}(\alpha)+\mathrm{B}_{2} \cos ^{2}(\alpha)+\mathrm{B}_{1} \cos (\alpha) \\
\mathrm{Y}=\sum_{\mathrm{n}=1}^{5} \frac{\pi}{\mathrm{n}+1} \mathrm{~A}_{\mathrm{n}}+\sum_{\mathrm{n}=1}^{5} \frac{\pi}{\mathrm{n}+1} \mathrm{~B}_{\mathrm{n}}
\end{gathered}
$$

The curve fits shown in Fig. 3 for the front (blue) and back (red) sputtered distributions were found by plotting the differential sputter yield data versus the cosine of the polar angle as shown in Fig. 4. The curve fit values $A_{n}$ and $B_{n}$ shown in Figs. 3 and 4 can be used in $\mathrm{Eq}$. (9) to estimate the total sputter yield of 0.22 atoms/ion. The cosine distribution curve plotted in Figs. 3 and 4 for comparison purposes was found using Eq. (3) assuming a total yield of 0.22 atoms/ion, which was equivalent to the total yield of the measured distribution as found using $\mathrm{Eq}$. (9). The cosine distribution is very different from the measured distribution, and this result reenforces the observation made earlier with normal incidence data that thruster erosion models using cosine (i.e., diffuse) emission of sputtered particles are not accurate for predicting sputtering behavior of carbon-based materials.

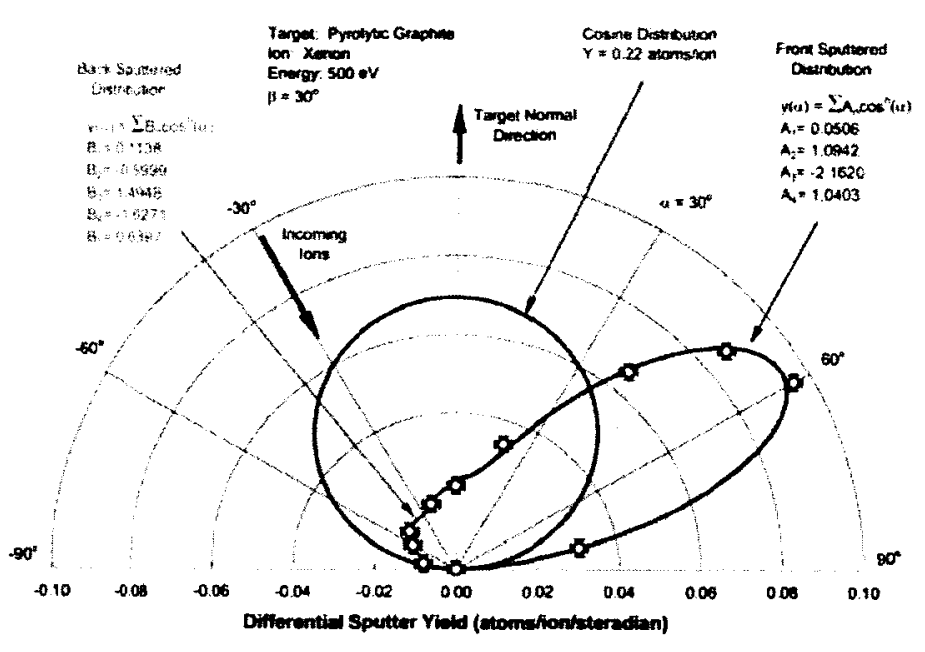

Fig. 3 Differential sputter yield data measured at an incidence angle of $30^{\circ}$ and ion energv of $500 \mathrm{eV}$.

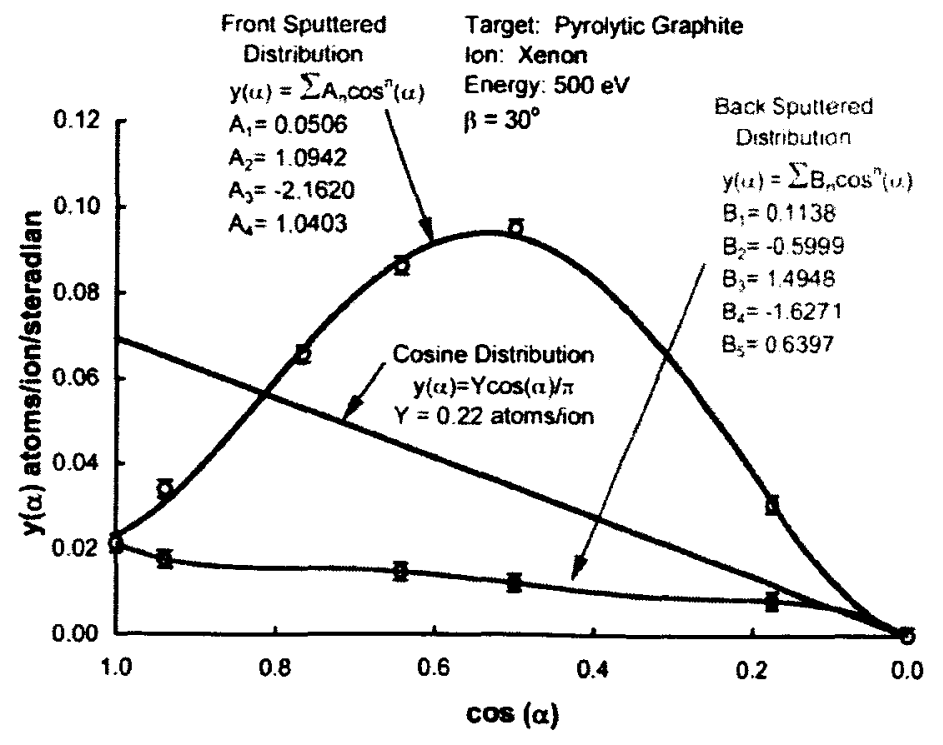

Fig. 4 Standard representation of differential sputter yield data. See Fig. 3 for a polar plot of the same data.
Although the pyrolytic graphite data show reasonable differential sputter yield patterns at high ion energies, this was not always the case in preliminary tests with combinations of low ion energies and high angles of incidence. We believe this observation is best explained by considering the ion source/target/QCM configuration shown in Fig. 5. The black arrow emanating from the ion source represents energetic beam ions that strike the target and sputter material from it. The other arrows pointing at the QCM are discussed below.

American Institute of Aeronautics and Astronautics 


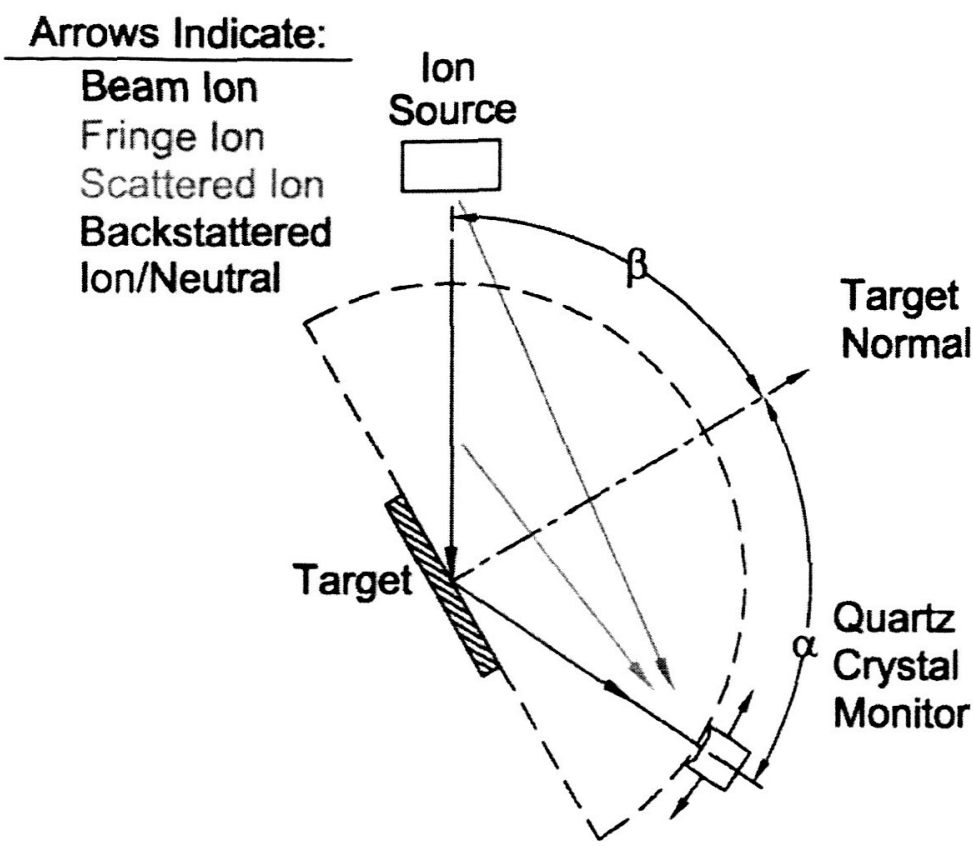

Fig. 5 Orientation of target at $60^{\circ}$ incidence $\left(\beta=60^{\circ}\right)$ with the QCM at $+120^{\circ}$ relative to the ion beam (and $+60^{\circ}$ rel to target normal).
For preliminary tests at 200 and 300 $\mathrm{eV}$ ion energy levels, the original NSTARlike gridlets used to produce the ion beam were disassembled and re-gapped at a smaller screen-to-accel spacing of $0.26 \mathrm{~mm}$. This was necessary to achieve better beam focusing and higher perveance operation for ion energy levels of 200 and $300 \mathrm{eV}$. At a $60^{\circ}$ angle of incidence of the ion beam relative to the target normal, however, we detected high rates of net removal of material from the deposition rate monitor (QCM) when it was positioned at high positive polar angles $(\alpha)$, sometimes by an amount greater than the maximum reading observed at any other QCM position. There was no reason to suspect that sputtering of the pyrolytic graphite target was not occurring. Instead, we suspected that material was being sputtered off of the $\mathrm{QCM}$ at a greater rate than its carbon accumulation rate. This rate of sputtering of the probe itself increased as the probe was moved closer and closer toward the ion beam axis (i.e., at higher values of $\alpha$ as shown in Fig. 5).

At least three possibilities exist that could explain this effect. The first possibility is that ions 'bounce' (or backscatter) off the carbon sample and continue with high kinetic energy toward the probe (see the blue arrow in Fig. 5) and sputter it. The sputtering could also be caused by direct impingement of highly divergent (fringe) ions (red arrow in Fig. 5) or by beam ions that are scattered (green arrow in Fig. 5). The fringe ions are those which are not tightly focused into the main beam as they leave the accelerator grid to the extent where they do not strike the target. As a reference to the reader, the fringe ion shown in Fig. 5 is at $22^{\circ}$ relative to the ion beam centerline Scattered beam ions are created within the entire column of the ion beam when an elastic collision occurs between a beam ion and a neutral atom. In some large angle collisions, the scattered ion or neutral atom can be deflected toward the QCM and still retain enough energy to sputter material from the probe.

A test was performed that isolated the effects of fringe and scattered ions from the backscattered particles. This was done by rotating the target normal direction to $\beta=-70^{\circ}$ while leaving the QCM at a high positive polar angle. The results from this test showed that fringe ions and scattered fast particles accounted for nearly all of the negative readings that were recorded during

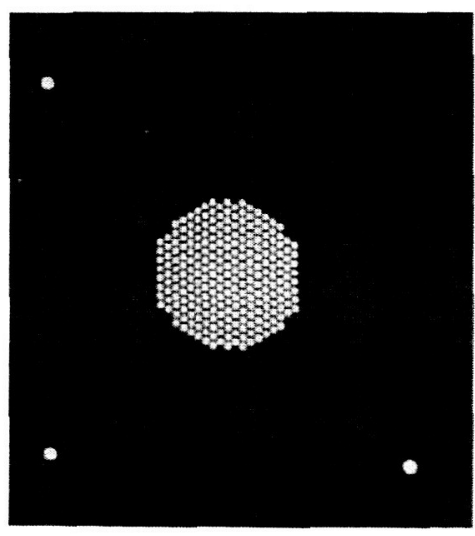

a) Screen gridlet ( $\sim 2 \mathrm{~cm}$ dia beam)

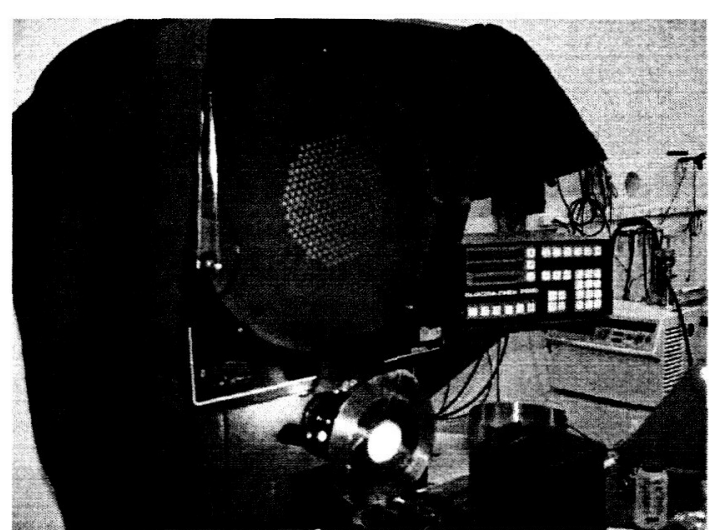

b) Gridlet assembly on optical comparitor
Fig. 6 Small hole gridlets fabricated for high perveance operation at low ion energies. 
sputtering tests. It is noted that this test was repeated at all of the xenon ion energies studied in this program, and the correction due to fringe and scattered ions was taken into account in the plots and data lists contained in the results section below.

To improve problems caused by a poorly focused ion beam at low ion energies, new gridlets were fabricated from Poco graphite sheets $(0.254 \mathrm{~mm}$ thick), which are shown in Fig. 6 . The screen and accel grid hole diameters were $0.95 \mathrm{~mm}$ and $0.64 \mathrm{~mm}$, respectively-about half the size of NSTAR apertures. The gridlet assembly shown in Fig. $6 \mathrm{~b}$ was used to take all sputter yield data at 200 and $300 \mathrm{eV}$.

\section{Results}

The results of this study are presented in three sections. The first section presents data measured with a pyrolytic graphite (PG) target while the second one presents data for a carbon-carbon composite (CC) target. The third section compares and contrasts the PG and $\mathrm{CC}$ data to each other and to measurements made by other researchers. In this section, comparisons of PG and CC data to molybdenum measurements are also made and a simple model is presented that predicts the life time enhancement of ion optics systems that use carbon-based materials rather than conventional refractory materials like molybdenum and titanium.

\section{A. Pyrolytic Graphite Sputter Measurements}

Figures 7 through 12 contain differential sputter yield data for PG that demonstrate the effects of xenon ion energy and angle of incidence. Figure 7 contains polar plots of data collected at $1000 \mathrm{eV}$ for angles of incidence of $0,5,15,30,45$, and $60^{\circ}$. The individual data points are not shown on the curves to reduce clutter on the figure, however, the data points scatter about the curves in a manner similar to that shown in Figs. 2 and 3.

In Fig. 7 note the dramatic difference between data taken at normal incidence $\left(0^{\circ}\right)$ and at an incidence angle of only $5^{\circ}$. The high sensitivity of the differential sputter yield measurements to incidence angle forced us to very carefully adjust the target normal and ion beam directions prior to taking measurements. In addition, the ion beam was aligned so that it would strike a position very close to the center of the target. To ensure this condition, we placed a thin tantalum foil plate directly into the ion beam at a location that was less than $1.0 \mathrm{~cm}$ above the center of the target. The tantalum foil indicated the beam center by glowing red at that location when the ion beam was directed onto it. The tantalum foil was mounted on a rod which could be both rotated and pushed into the vacuum system via a feed-through. In this way, the probe could be moved over the target to check beam alignment, and then be rotated underneath the water cooled target where it would be protected from the beam when not in use. This could all be done while the system was under vacuum and while the ion beam was operating under steady state conditions.

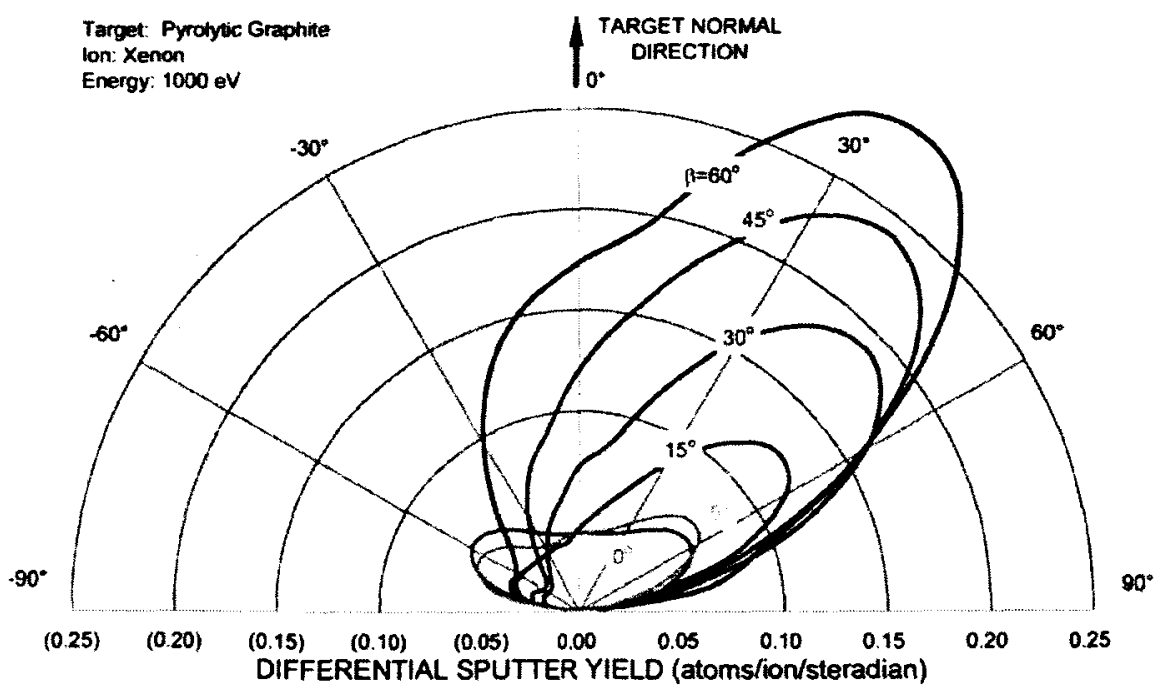

Fig. 7 Sputter yield data for pyrolytic graphite bombarded by $1000 \mathrm{eV}$ xenon ions. 
After carefully aligning the ion beam to the target, the data shown in Fig. 8 were collected at normal incidence over a range of ion energies from $200 \mathrm{eV}$ to $1000 \mathrm{eV}$. It is interesting to note the shift from under cosine behavior observed at $1000 \mathrm{eV}$ to more cosine-like behavior at 200 and $300 \mathrm{eV}$. For low energy ion bombardment, it is believed that atoms knocked into high polar angle directions may not obtain enough energy to overcome the surface binding energy and escape from the surface with high probability.

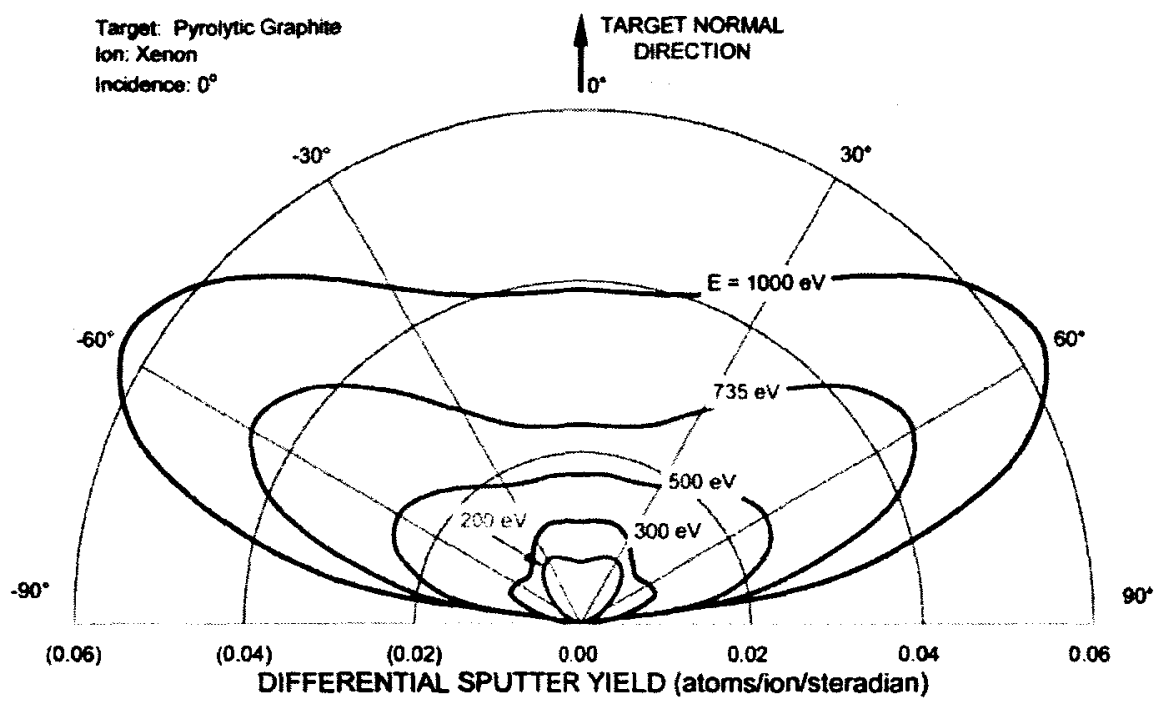

Fig. 8 Sputter yield data for pyrolytic graphite bombarded at normal incidence.

Figures $9,10,11$, and 12 contain polar plots of differential sputter yield data versus ion incidence angle that were measured at xenon ion energies from $735 \mathrm{eV}$ down to $200 \mathrm{eV}$. In general, the $735 \mathrm{eV}$ data shown in Fig. 9 behave similarly to the $1000 \mathrm{eV}$ data shown in Fig. 7. The most notable differences are that the $735 \mathrm{eV}$ yields are lower (as expected) and that the $60^{\circ}$ incidence data at $735 \mathrm{eV}$ is shifted toward the ion beam.

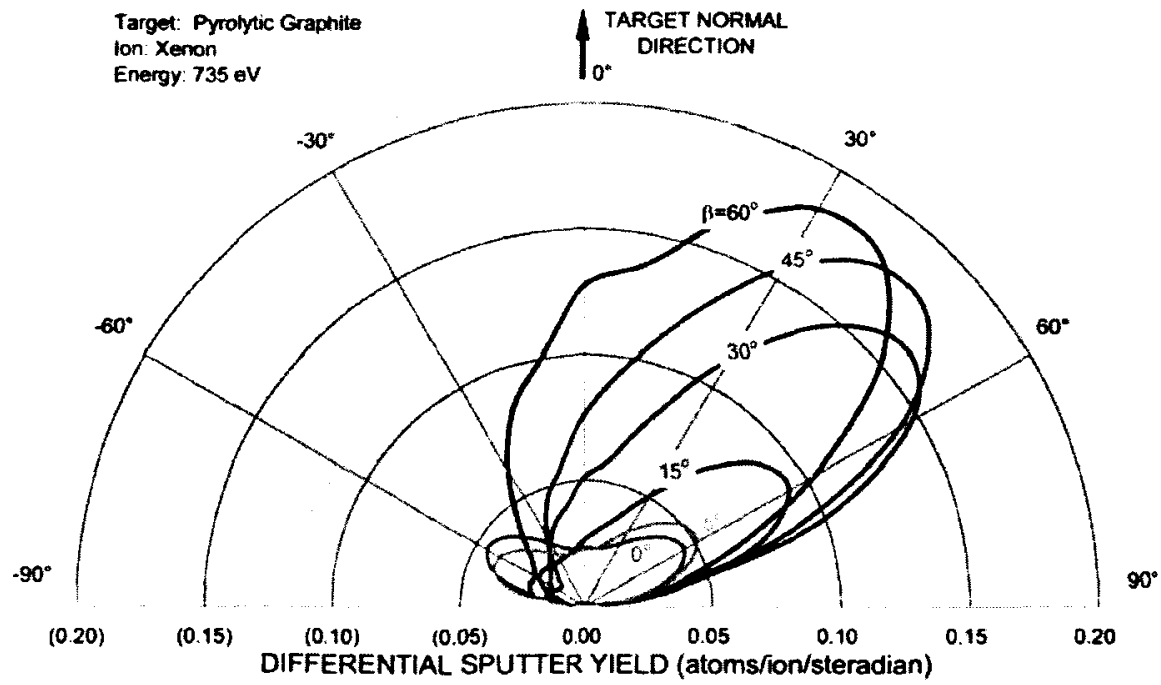

Fig. 9 Sputter yield data for pyrolytic graphite bombarded by $735 \mathrm{eV}$ xenon ions. 
Figure 10 contains data collected at $500 \mathrm{eV}$. The $0^{\circ}, 15^{\circ}, 30^{\circ}$, and $45^{\circ}$ data are similar in shape to the 735 $\mathrm{eV}$ (Fig. 9) and $1000 \mathrm{eV}$ (Fig. 7) data, however, the $60^{\circ}$ incidence data drops below the $30^{\circ}$ and $45^{\circ}$ data in the front-half hemisphere region (i.e., at positive polar angles). It is possible that the $500 \mathrm{eV}$ ions arriving at the target at $60^{\circ}$ incidence do not transfer as much energy to near-surface atoms (compared to $500 \mathrm{eV}$ ions at $30^{\circ}$ and $45^{\circ}$ ), which are then less effective at escaping from the surface or colliding with other atoms and transferring enough energy to cause the knock-on atoms to escape. This is an interesting result because it suggests that pyrolytic graphite may perform better in highly oblique ion bombarding situations that occur on the accel grid in three-grid ion optics systems for example.

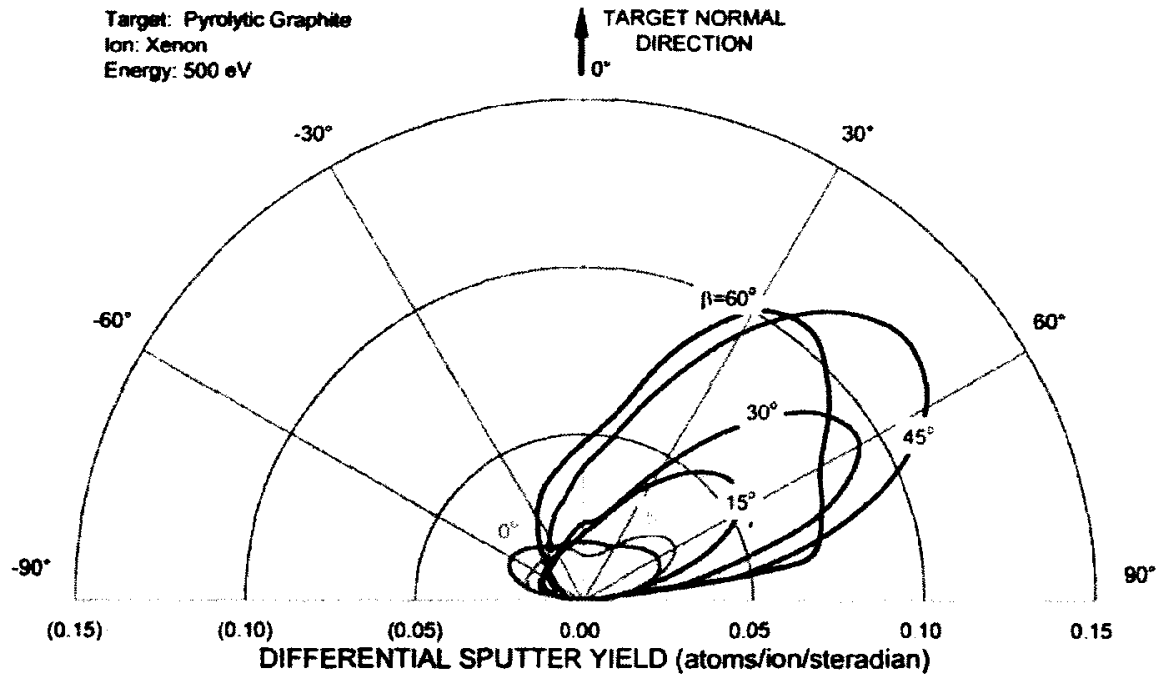

Fig. 10 Sputter yield data for pyrolytic graphite bombarded by $500 \mathrm{eV}$ xenon ions.

Figures 11 and 12 contain $300 \mathrm{eV}$ and $200 \mathrm{eV}$ polar plots, respectively. As noted earlier, the normal incidence curves appear more cosine-like. This could be due to atoms knocked into high polar angles directions not having enough energy (under the $200 \mathrm{eV}$ and $300 \mathrm{eV}$ bombarding conditions) to escape the surface with high probability. In addition, note that Fig. 11 shows both the $45^{\circ}$ and $60^{\circ}$ incidence curves falling below the $30^{\circ}$ curve in the front half of the hemisphere. Again, this could be due to reduced emission probabilities at high polar angles due to a poor energy transfer situation. In Fig. 12, the $60^{\circ}$ incidence data are shown to increase dramatically in the $30^{\circ}$ to $+30^{\circ}$ region. Although the $\beta=60^{\circ}$ distribution appears to be quite large, the total yield in atoms/ion is lower than the $30^{\circ}$ distribution, which is caused by geometrical arguments that lead to the $\sin (\alpha)$ term in Eq. (5).

Table 1 contains a detailed list of the sputter yield data collected on pyrolytic graphite. It includes $A_{n}$ and $B_{n}$ coefficients (see Eqs. (7) and (8)) along with total yield estimates obtained using Eq. (9). Figure 13 contains a plot of total sputter yield data listed in Table 1 versus incidence angle for pyrolytic graphite that was bombarded with $200 \mathrm{eV}$ to $1 \mathrm{keV}$ xenon ions. At $1 \mathrm{keV}$, the sputter yield was observed to increase with incidence angle up to values that were about 2.5 times those measured at normal incidence. As mentioned earlier, it is interesting to note how the total yield of pyrolytic graphite appears to stop increasing with incidence angles above $45^{\circ}$ at energies below $735 \mathrm{eV}$. 


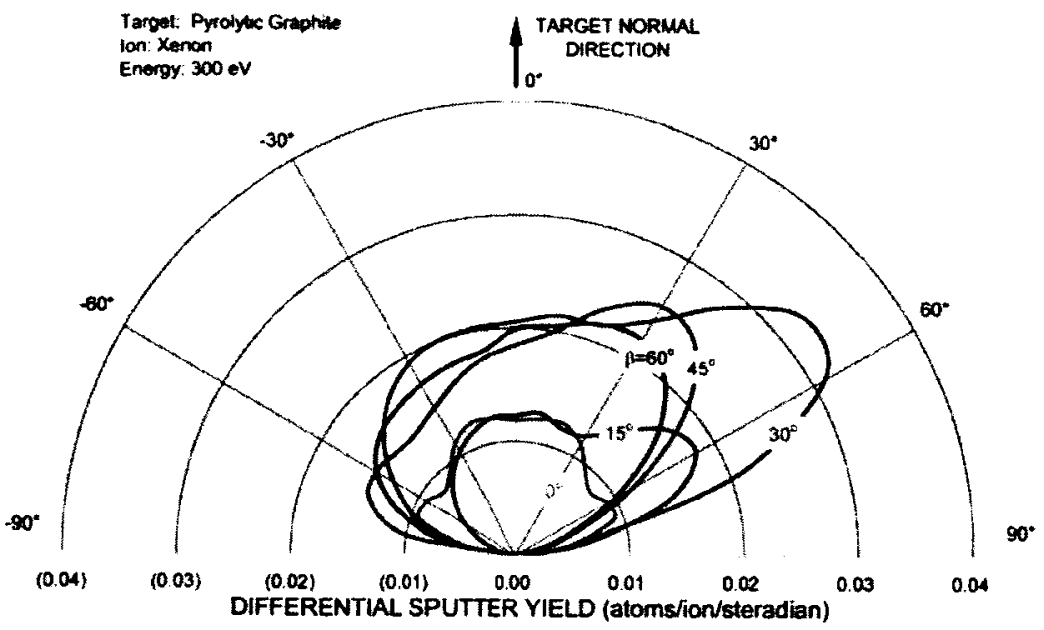

Fig. 11 Sputter yield data for pyrolytic graphite bombarded by $300 \mathrm{eV}$ xenon ions.

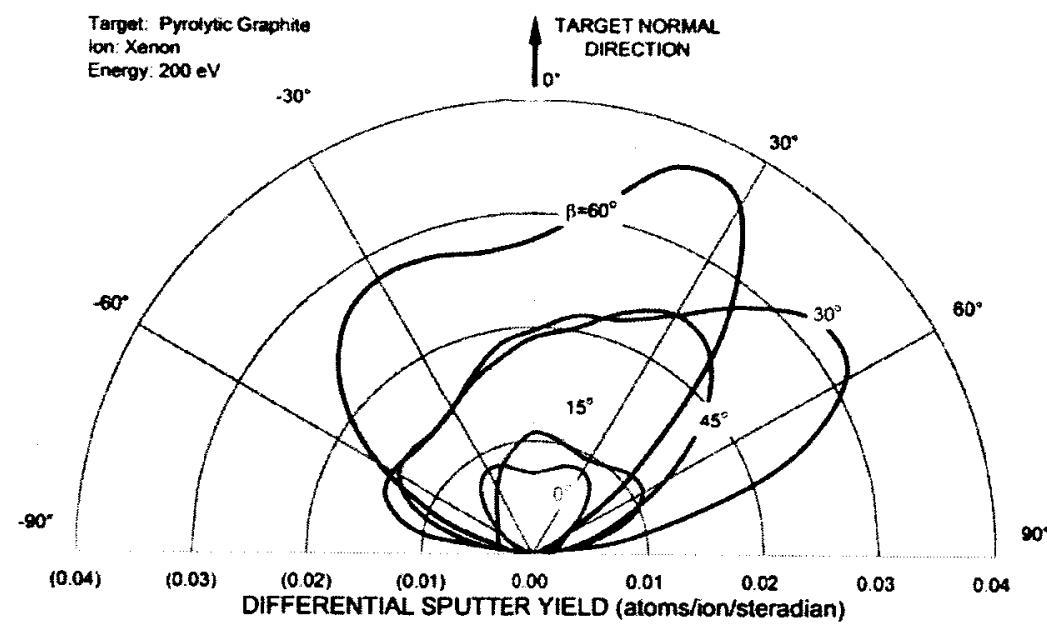

Fig. 12 Sputter yield data for pyrolytic graphite bombarded by $200 \mathrm{eV}$ xenon ions.

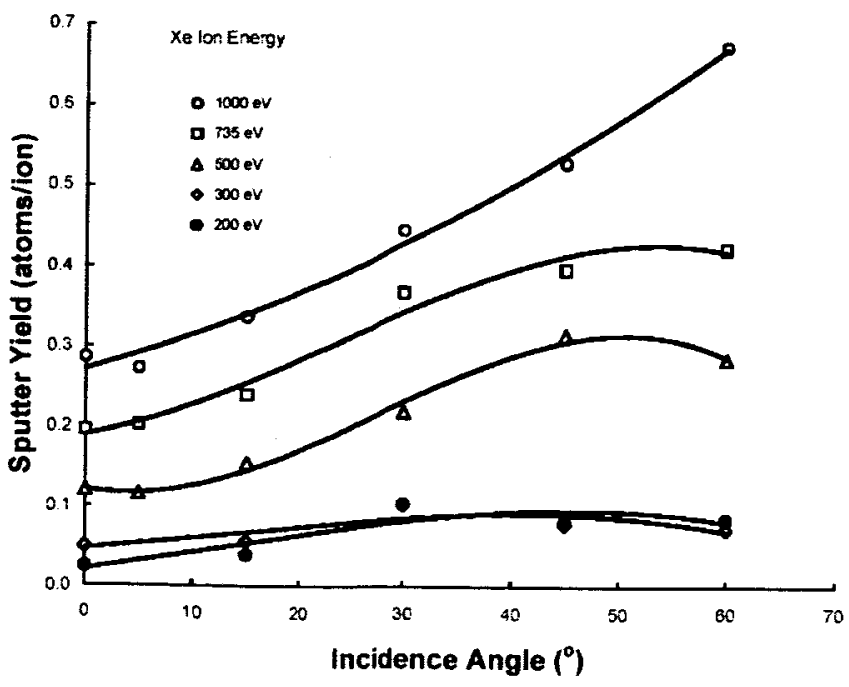

Fig. 13 PG total sputter yield behavior as a function of incidence angle and ion energy. 
TABLE 1 Sputter yield data for pyrolytic graphite bombarded by xenon ions at normal and oblique incidence.

\begin{tabular}{|c|c|c|c|c|c|c|c|c|c|c|c|c|c|}
\hline \multirow[b]{2}{*}{ E } & \multirow{3}{*}{$B$} & \multirow[b]{2}{*}{ Target } & \multirow[b]{2}{*}{ Y } & \multicolumn{3}{|c|}{ Front Coefticients (atomsion'steradian) } & \multicolumn{2}{|l|}{ See Eq $(7)$} & \multicolumn{3}{|c|}{ Back Coefficients (atomsion/steradian) } & \multirow{2}{*}{$\begin{array}{c}\text { See Eq. (8) } \\
\text { B2 }\end{array}$} & \multirow[b]{2}{*}{ B1 } \\
\hline & & & & A5 & A4 & A3 3 & A2 & 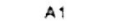 & B5 & B4 & D & & \\
\hline$(e V)$ & & & (atomsín) & & & & & & & & & & \\
\hline 200 & 60 & PG & 0084 & $2296 E+00$ & $2 E+\infty$ & $.17947 E+00$ & $44741 E-01$ & $-26524 E-02$ & 0000 & 0000 & $84712 E-02$ & $1.1670 E-01$ & $.5 .4383 E \cdot 03$ \\
\hline 200 & 45 & PG & 0.081 & 0.000 & $1.4745 E-01$ & $20307 E .01$ & $6.1100 E .02$ & $2.4595 E-02$ & 0.000 & 0000 & $8.0513 E .02$ & $-1.4219 E .01$ & $79794 \mathrm{E} \cdot 02$ \\
\hline 200 & 30 & PG & 0.104 & 0.000 & $3.1910 E-01$ & $-66920 E-01$ & $36323 E-01$ & $8.2052 \mathrm{E}-03$ & 0.000 & $1.4590 \mathrm{E}-01$ & $-2.4722 E-01$ & $9.9522 E-02$ & $2.1434 E-02$ \\
\hline 200 & 15 & PG & 0.038 & 0.000 & $99146 E \cdot 02$ & $-18071 E-01$ & $7.5293 \mathrm{E} .02$ & $1.7001 E \cdot 02$ & 0.000 & 0000 & 3. $1807 E-02$ & $-4.2888 E .02$ & $2.1104 E \cdot 02$ \\
\hline 200 & 0 & $P G$ & 025 & $\mathrm{mo}$ & $86046 E$ & & -6 3707E.02 & 1.2698 & and & 60 & $4425 E-01$ & E.02 & $12698 \mathrm{E}-02$ \\
\hline 300 & 60 & PG & 0.072 & 0.000 & $.7 .5705 E-02$ & 68741 E.02 & $2.9258 E-02$ & $-2.3862 E-03$ & 0.000 & 4.1429 & $\mathrm{E}-02$ & -02 & 3.5283E-02 \\
\hline 300 & 45 & $P G$ & 2078 & 0,000 & $-1.7056 \mathrm{E}-01$ & $2.1523 E-01$ & $-3.4227 E .02$ & 8.225 & 0.000 & 0.0 & & & $=02$ \\
\hline 300 & 30 & $P G$ & 103 & 00 & 4.73 & $-1.0170 E+00$ & 6.1658E.01 & $5.0939 E-02$ & 0.000 & $-49465 E-02$ & BE.01 & .02 & 4.4764E-02 \\
\hline 300 & 15 & $P G$ & 056 & 0.000 & 2.39 & $45665 \mathrm{SE}-01$ & 2.1941E.01 & $10834 \mathrm{E}-02$ & 0.000 & $2.3515 E-02$ & $-5.3972 E-02$ & $4.3165 E-02$ & $.2 .5552 \mathrm{E}-04$ \\
\hline 300 & 0 & $P G$ & 050 & $9800 E-01$ & & & 3.3483 & -5.139 & 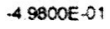 & & & & \\
\hline 500 & 60 & $P G$ & 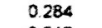 & & & 3 & & & 0 & & & & \\
\hline 500 & 45 & $P G$ & 112 & & 2 & -10 & -95 & 3.15 & 0. & & & & $E .02$ \\
\hline 500 & 30 & $P G$ & 0.218 & 0.000 & 1.040 & .2 .1620 & 10942 & 5.060 & 3970E 09 & $-6271 E+\infty 0$ & 1.4 & .59990 & 1.1380E.01 \\
\hline 500 & 15 & $P G$ & 153 & & & -86 & & 1.285 & 0.000 & & & & 1E.09 \\
\hline 500 & 5 & $P G$ & 0.115 & 000 & 2.739 & .5 .48 & 2.4696 & 4.1532 & 0.000 & .2 & .01 & 01 & $1.4908 E-01$ \\
\hline 500 & 0 & $P G$ & 0.120 & 200 & $6.7586 \mathrm{E}-02$ & .57 & .9764 & $1.0491 \mathrm{E}-01$ & 0.000 & 02 & E.02 & $E .02$ & $1.0291 E-09$ \\
\hline 735 & 60 & & & & & & & 182 & & & & & \\
\hline 735 & 45 & PG & 394 & & & & & .5249 & 0.0 & 00 & & & $1.4905 \mathrm{E}-01$ \\
\hline 735 & 30 & $P G$ & 366 & & & & & -5.87 & & & & & $9.7 \$ 22 \mathrm{E} \cdot 02$ \\
\hline 735 & 15 & $P G$ & 0.238 & o & 87 & -93 & & 8690 & 0000 & 1782 & .32 & & $3.2723 \mathrm{E} .02$ \\
\hline 735 & 5 & $P G$ & 0.202 & 0 & & & & & 0.00 & & & & $1.8849 E-01$ \\
\hline 735 & 0 & $P G$ & 0.196 & 200 & $3.2696 \mathrm{E}-01$ & $-6.0936 \mathrm{E}-01$ & 2.0830E-01 & $9.7324 \mathrm{E}-02$ & 0,000 & $32695 \mathrm{E}-01$ & $-60936 \mathrm{E}-01$ & 2 C830E-01 & $9.7324 \mathrm{E} \cdot 02$ \\
\hline 300 & 60 & & 0. & & & & & & & & & & \\
\hline$\infty 00$ & 45 & & 0 & & & & & 1.05 & 00 & & & & E-01 \\
\hline$\infty$ & 30 & & & & & .11217 & $95166 \mathrm{E}-01$ & $1.1116 E-01$ & 0000 & 0000 & 84E-01 & $99 E-01$ & $1.5686 \mathrm{E}-01$ \\
\hline 1000 & 15 & $P G$ & 0.335 & $m$ &.$\infty$ & .257 & 1.6210 & $67481 \mathrm{E}$ & 0.0 & $-12897 E-01$ & E-01 & $72 E-01$ & $2.2065 \mathrm{E}-01$ \\
\hline 100 & 5 & & 0.27 & & & .17111 & 1.0241 & 47607 & 00 & $20519 E-01$ & .01 & 93E-01 & $2.5779 E=0$ \\
\hline 1000 & 0 & $P G$ & 0286 & 0.000 & $34081 E-01$ & $.60599 E-01$ & $13909 E D 1$ & $16501 E-01$ & 0000 & $340 B 1 E-01$ & $60599 E-01$ & $13909 \mathrm{E}-01$ & $15501 \mathrm{E}-01$ \\
\hline
\end{tabular}

Photographs taken before and after the sputter testing show very little difference as documented in Fig. 14. Note however that all of the samples tested during this program were tested in an as received condition, and no pretest polishing or cleaning was performed. The roughness $\left(R_{a}\right)$ of the samples before testing was measured to be $\sim 1.8 \mu \mathrm{m}$. It is possible that the sputtering behavior of the surface will change as it becomes highly eroded. In order to check this possibility, we performed temporal experiments where an initially un-exposed pyrolytic graphite sample was subjected to the same sputtering conditions over many hours while periodic measurements were made of the differential sputter yield profile. The results of testing conducted at $1000 \mathrm{eV}$ and $30^{\circ}$ incidence are shown in Fig. 15 as a plot of total yield versus trace number. As indicated in the figure, each test sequence was followed by a 2 to $3 \mathrm{hr}$ sputtering period before the measurements were repeated. The sputter yield is shown to level out near 0.41 atoms/ion after about 6 test sequences. The scatter in the data is about $\pm 10 \%$, and it is noted that Table 1 lists the sputter yield at 0.44 atoms/ion for the $1000 \mathrm{eV}, 30^{\circ}$ sputtering condition performed on a separate pyrolytic graphite sample.

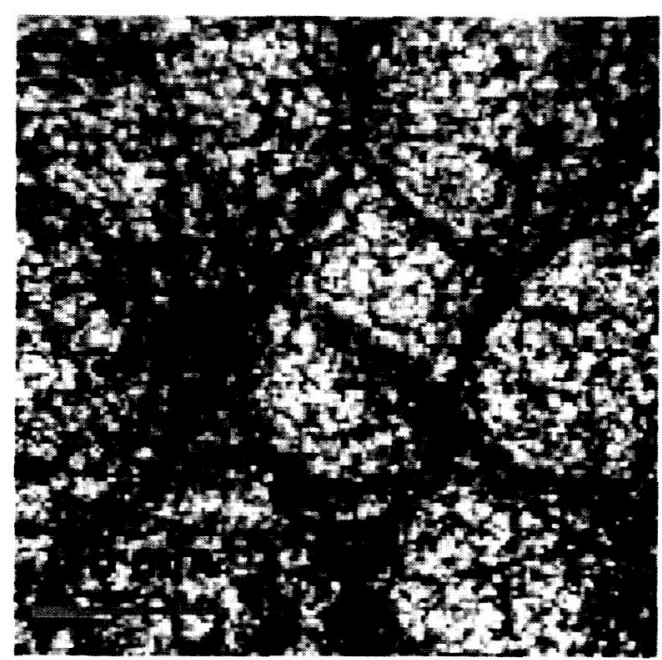

a) Before testing

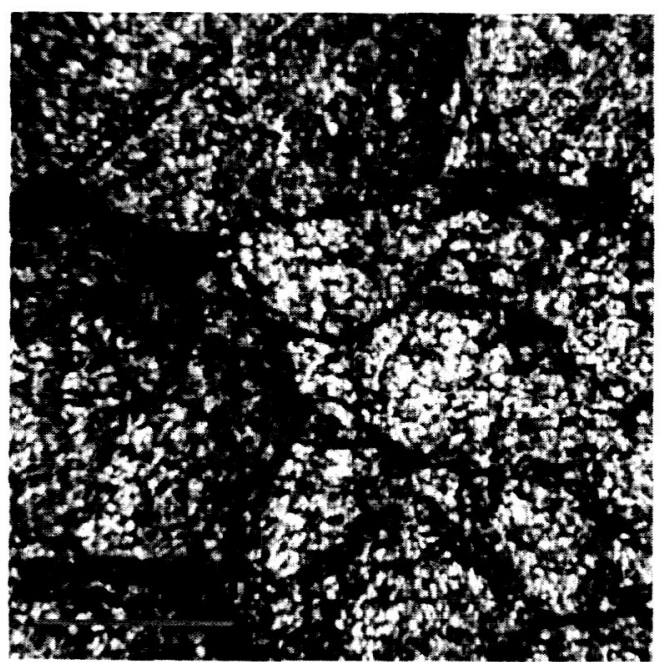

b) After testing

Fig. 14 Photographs of the pyrolytic graphite surface taken before and after sputter testing. 


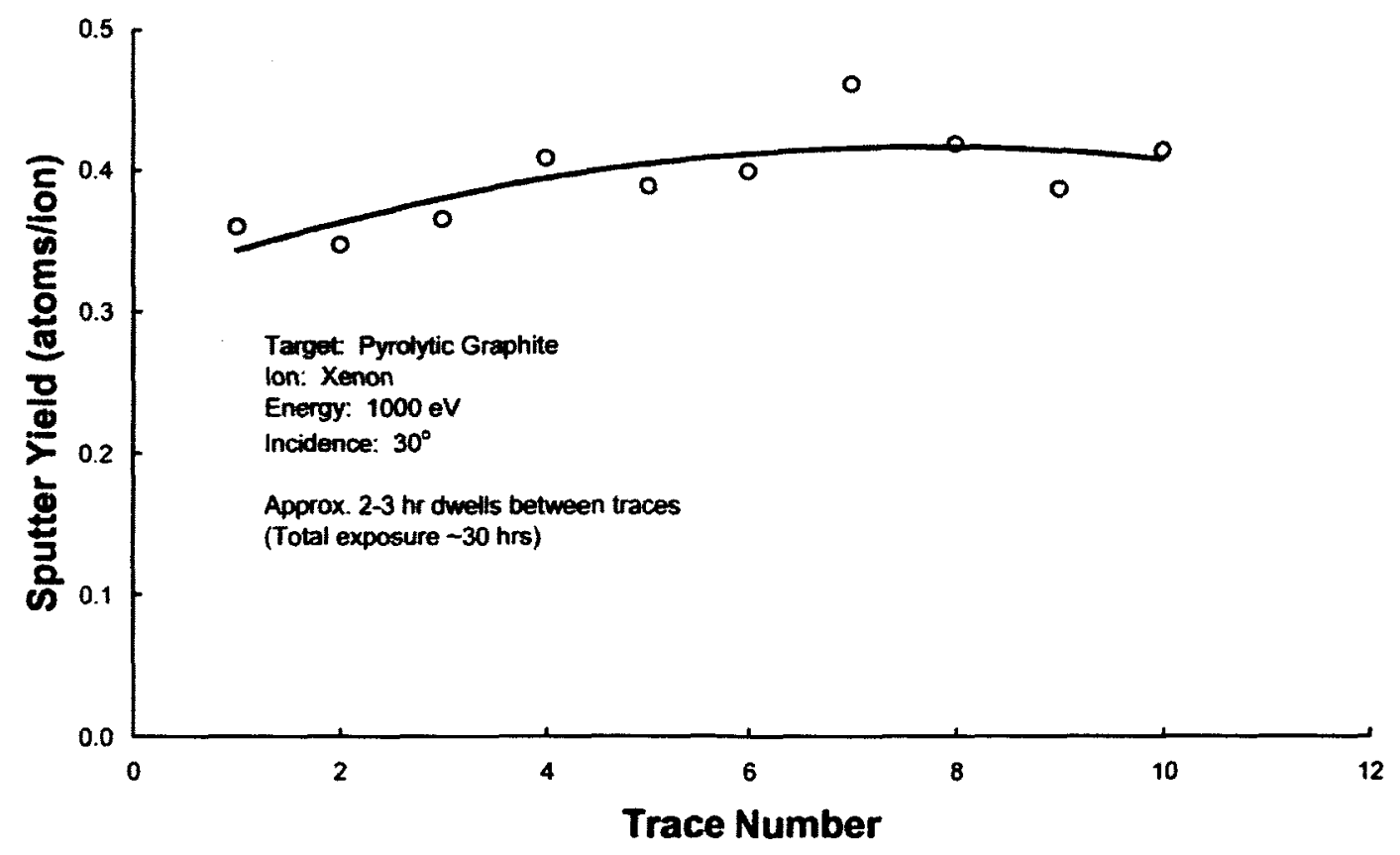

Fig. 15 Results of temporal measurements of PG sputter yields at $1000 \mathrm{eV}$ and $30^{\circ}$ incidence.

\section{B. Carbon-Carbon Composite Sputter Measurements}

Figures 16 through 22 contain differential sputter yield data for $\mathrm{CC}$ that can be compared to PG data shown in Figs. 7 through 13. Although there are some subtle differences between the CC and PG data, the overall similarity between the two materials is very high, and the results presented in the figures suggest that the PVD infiltrated and pyro-coated carbon-carbon composite material is virtually identical to pyrolytic graphite in terms of its sputtering behavior.

The easiest way to contrast the PG and CC data sets is through comparisons between Figs. 13 (PG) and 22 (CC), which show total sputter yield variation with energy and incidence angle. In general, $\mathrm{CC}$ total yields drop off less with incidence angle compared to PG yields. In addition, data collected at $200 \mathrm{eV}$ and $300 \mathrm{eV}$ are easier to distinguish from one another for $\mathrm{CC}$ than they are for PG. Table 2 contains a detailed list of the sputter yield data collected on CC, which is formatted similarly to the PG data contained in Table 1.

Similar to the PG sample, it is possible that the sputtering behavior of the CC surface will change as it becomes highly eroded. In order to check this possibility, we performed temporal experiments where an initially unexposed CC sample was subjected to the same sputtering conditions over many hours while periodic measurements were made of the differential sputter yield profile. The results of testing conducted at $1000 \mathrm{eV}$ and $30^{\circ}$ incidence are shown in Fig. 23 as a plot of total yield versus trace number. (Note that the equivalent test was conducted for PG and was documented in Fig. 15 above.) As indicated in the figure, each CC test sequence was followed by a 2 to 3 $\mathrm{hr}$ dwell before the measurements were repeated. The sputter yield is shown to be relatively constant at 0.6 atoms/ion during the entire test. The scatter in the data is about $\pm 10 \%$, and it is noted that Table 2 lists the sputter yield at 0.50 atoms/ion for the $1000 \mathrm{eV}, 30^{\circ}$ sputtering condition performed on a separate carbon-carbon sample. The error between measurements on the two CC samples was about $20 \%$. 


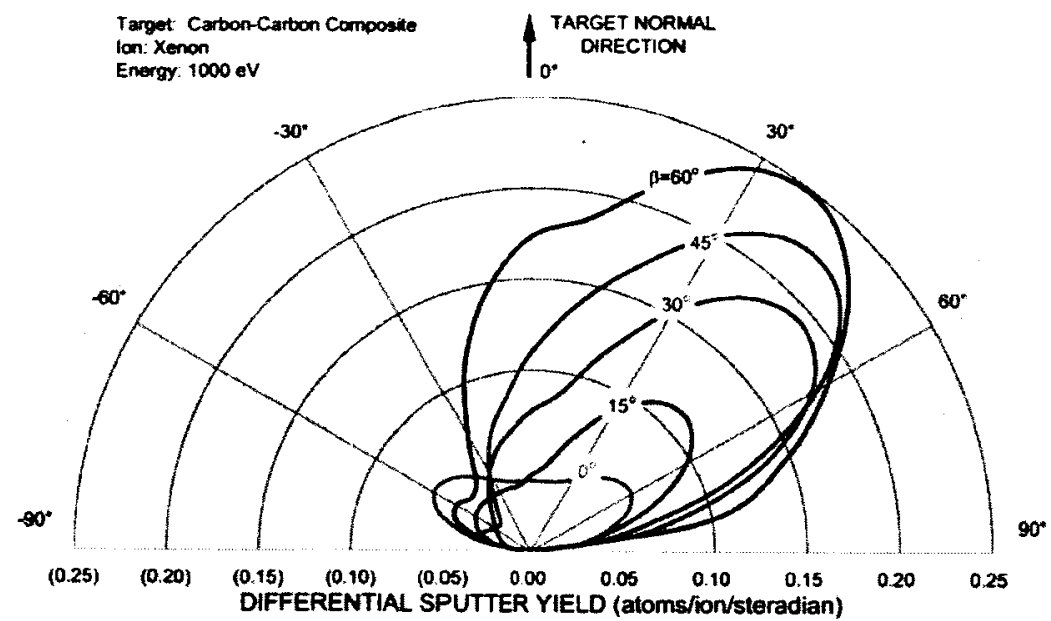

Fig. 16 Sputter yield data for carbon-carbon composite bombarded by $1000 \mathrm{eV}$ xenon ions.

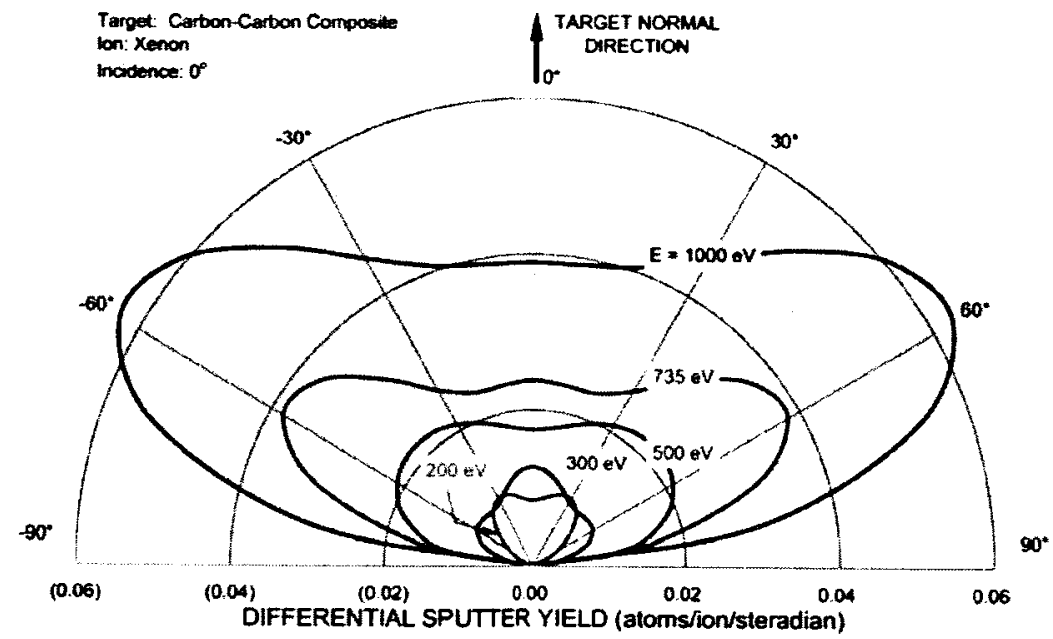

Fig. 17 Sputter yield data for carbon-carbon composite graphite bombarded at normal incidence.

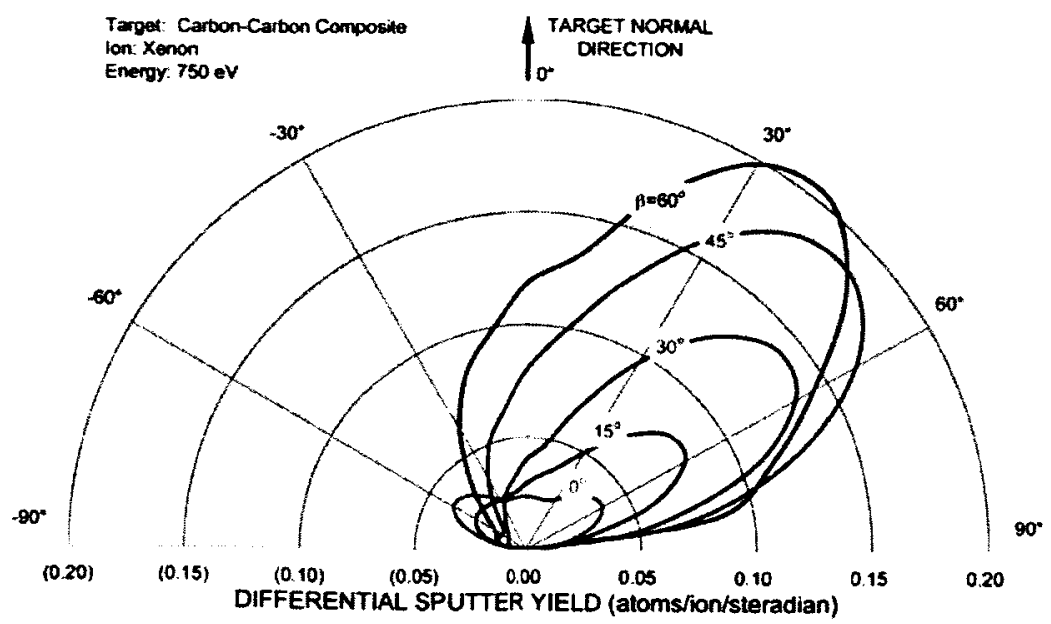

Fig. 18 Sputter yield data for carbon-carbon composite bombarded by $750 \mathrm{eV}$ xenon ions. 


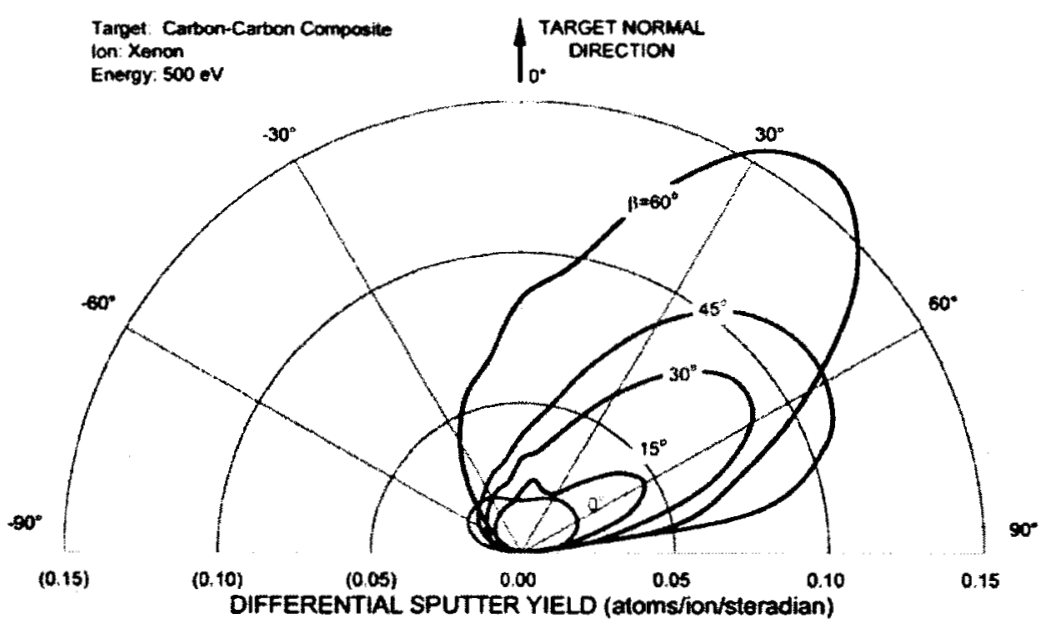

Fig. 19 Sputter yield data for carbon-carbon composite bombarded by $500 \mathrm{eV}$ xenon ions.

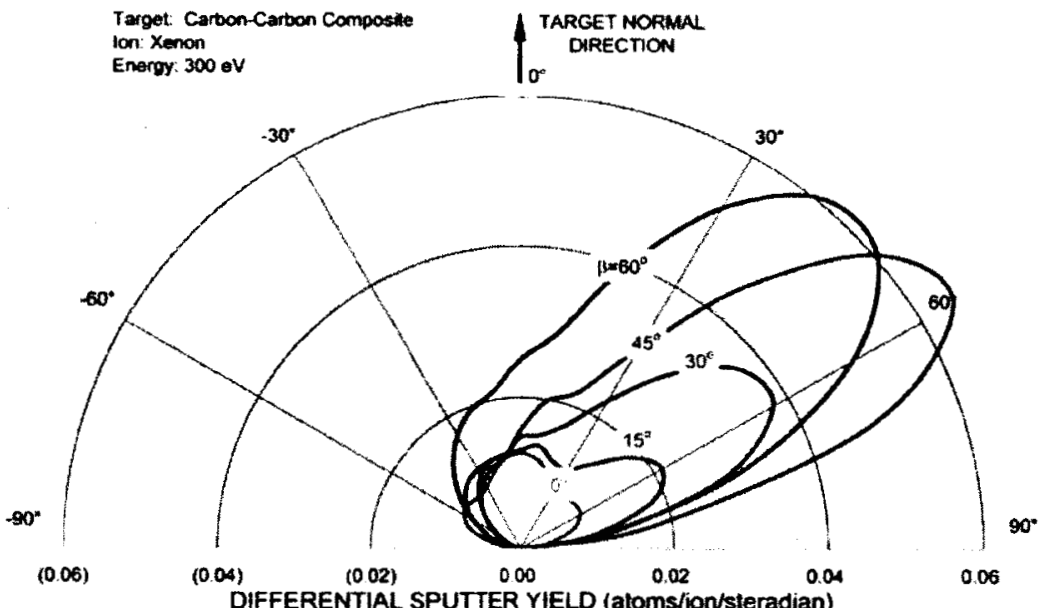

Fig. 20 Sputter yield data for carbon-carbon composite bombarded by $300 \mathrm{eV}$ xenon ions.

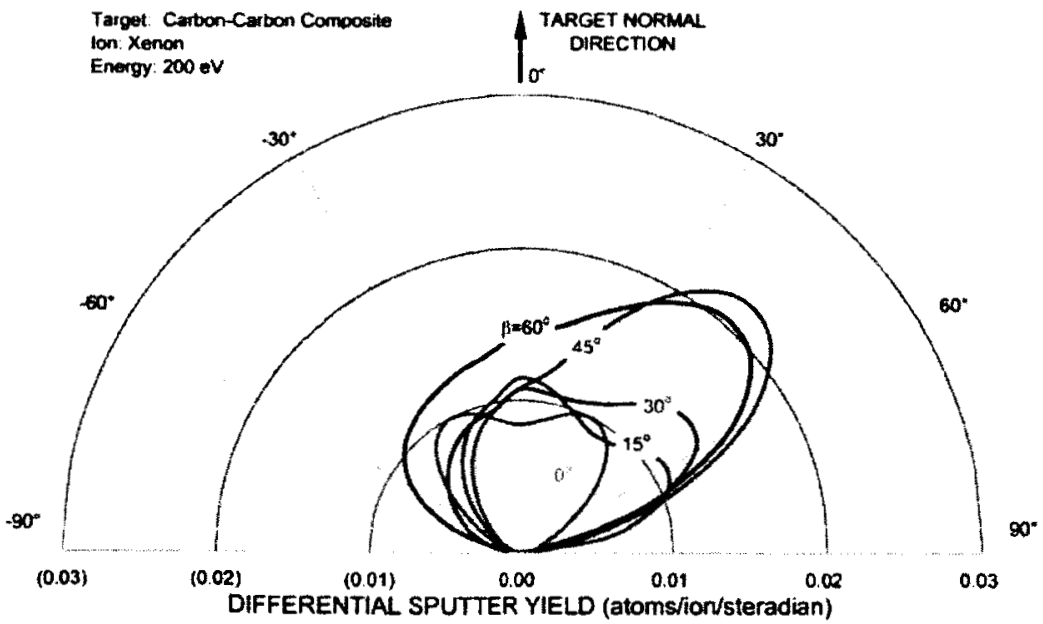

Fig. 21 Sputter yield data for carbon-carbon composite bombarded by $200 \mathrm{eV}$ xenon ions. 
TABLE 2 Sputter yield data for carthon-carbon composite bombarded by xenon ions at normal and oblique incidence.

\begin{tabular}{|c|c|c|c|c|c|c|c|c|}
\hline \multirow{3}{*}{$\underset{(o v)}{E}$} & \multirow{3}{*}{ (") } & \multirow[b]{2}{*}{ Target } & \multirow{3}{*}{$\underset{\text { atometion) }}{Y}$} & \multicolumn{3}{|c|}{ From Coetliciems (utomshonyaredian) } & \multicolumn{2}{|l|}{$\operatorname{sen} E q(7)$} \\
\hline & & & & A5 & A4 & $\mathbf{A 3}$ & $\mathbf{1 2}$ & A1 \\
\hline & & & & & & & & \\
\hline 200 & 60 & $\infty$ & 0.051 & 0.000 & $8.3633 E-02$ & $-2.5967 E-01$ & $2.0980 E 01$ & $-1.9319 E-02$ \\
\hline 200 & 45 & $\infty$ & 0.050 & 0.000 & 0.000 & $-1,1379 E-01$ & $1.2457 E-01$ & 8.6565E-06 \\
\hline 200 & 30 & $\infty$ & bous & 0.000 & $\$ .5691 E-01$ & $-3.3207 E-01$ & $1.8233 E_{0.01}$ & $-6.4320 E-03$ \\
\hline 200 & 15 & $\mathrm{cc}$ & 0.037 & 0.000 & BSBE-02 & -1.1904E-01 & $1.2806 E-02$ & 3.SOA $7 E$-OR \\
\hline 200 & 0 & $\infty$ & 0.020 & 0.000 & $-1.0036 E-01$ & $1.6824 \mathrm{E}-01$ & $.7 .4301 E .02$ & $1.4810 E-02$ \\
\hline 300 & 60 & $\infty$ & 0.145 & 0.000 & 0.00 & .3 .081 & $3.1323 E-01$ & 1.989 \\
\hline 300 & 45 & $\infty$ & 0.136 & 0.000 & 9.4960E-01 & $-1.9559 E+\infty$ & $1.05206+\infty$ & +2.65006 .02 \\
\hline$\infty$ & 30 & $\infty$ & 0.00 & 0.000 & $4.0011 E-01$ & $-8.4215 E-01$ & A. A137E-01 & 1.5460E- 02 \\
\hline 300 & 15 & $\infty$ & 0.050 & 0.000 & 2.7806E-01 & -4,849TE-01 & 1.987AE-01 & $3.1976 E-02$ \\
\hline 300 & 0 & $\infty$ & 0.006 & 0.000 & 9.8USSE-DR & $.16773 E-01$ & 6.8552E-02 & 1.33BAE-02 \\
\hline 100 & 60 & cc & 0.370 & 0.000 & $-1.5817 E+\infty$ & $2.5900 E+00$ & $-1.364 \mathrm{E}+\infty$ & - So10E-01 \\
\hline 500 & 45 & $\infty$ & 329 & 1.000 & $\cdot 7.8264 E-01$ & 1.639 & -1.463 & $6.4782 E-01$ \\
\hline 00 & 30 & $\infty$ & 0.224 & 0.000 & 5.5504E-01 & $-1.3345 E+\infty 0$ & $7.4773 E-01$ & $6.3142 E-02$ \\
\hline & 15 & $\infty$ & 1116 & 0.000 & $8.0700 \mathrm{E}-09$ & $-1.5497 E+\infty 0$ & $78035 E-01$ & $-1,1083 E-02$ \\
\hline$\infty$ & 0 & $\infty$ & 0.110 & 0.000 & $-7.5102 E .02$ & $17771 E-01$ & $-1.8432 E-01$ & $9.9198 E-02$ \\
\hline 750 & $\infty$ & $c c$ & .516 & 0,000 & $-2.3780 E+00$ & $42912 E+\infty$ & $=+\infty$ & 8.1699E-01 \\
\hline 80 & 45 & $\infty$ & 37 & 0.000 & $-5,1244 E-01$ & & 4 & $46008 E-01$ \\
\hline 750 & 30 & $\infty$ & 0.330 & 0.000 & $3.8140 E-01$ & $-1.1050 E+00$ & $5,3283 E 01$ & 2.3002E-01 \\
\hline 750 & 15 & $\infty$ & 0.228 & 0.000 & 6.9240E-01 & $-1.944 \mathrm{E}+00$ & $1.1009 E+\infty$ & $-1.68 B 4 E-02$ \\
\hline 50 & 0 & ce & 0.166 & 0.000 & $3.6483 E-01$ & $-7.0004 E-01$ & $3.0632 E-01$ & $5.2717 E-02$ \\
\hline$\infty$ & 60 & $\infty$ & 0.6 & 00 & $A E+\infty$ & 358 & $E+\infty$ & \\
\hline$\infty$ & 45 & $\infty$ & 0.541 & 0.000 & 9.9755E-04 & -8.93 & 8.7232E-01 & 1.4625E-01 \\
\hline$\infty$ & 30 & $\infty$ & 0.495 & 0.000 & 0.000 & $-5.2636 E-01$ & 2 4M98E-01 & $36007 E-01$ \\
\hline & 15 & $\infty$ & 0.323 & 0.000 & 0.000 & $-4,3195 E-01$ & $33929 E-01$ & 1.3382E-01 \\
\hline & 0 & 象 & 0.286 & 0.000 & $3.4061 E-01$ & $-6.0599 E-01$ & $1.3909 E-01$ & $1.6501 E-01$ \\
\hline
\end{tabular}

\begin{tabular}{|c|c|c|c|c|}
\hline$c * \mathrm{C}$ & is 1 & im) & 8 & \\
\hline B5 & $B A$ & B3 & B2 & B1 \\
\hline $\begin{array}{l}0.000 \\
0.000 \\
0.000 \\
0.000 \\
0.000\end{array}$ & $\begin{array}{c}7.0916 E-02 \\
0.000 \\
-2.5626 E-03 \\
0.000 \\
-1.0036 E-01\end{array}$ & $\begin{array}{l}1.5352 E-01 \\
1.2915 E-02 \\
5.1630 E-03 \\
.2 .004 E-03 \\
1.6924 E-01\end{array}$ & $\begin{array}{c}9.9807 E-02 \\
-5.6771 E-03 \\
-3.5003 E-03 \\
1.8111 E-02 \\
-7.4301 E-02\end{array}$ & $\begin{array}{r}3.7219 E-03 \\
2.8373 E-03 \\
1.0825 E-02 \\
-3.1683 E-03 \\
1.4810 E-02\end{array}$ \\
\hline $\begin{array}{l}0.000 \\
0.000 \\
0.000 \\
0.000 \\
0.000\end{array}$ & $\begin{array}{c}0.000 \\
0.000 \\
1.2024 E-02 \\
-4.6025 E-02 \\
9.8095 E-02\end{array}$ & $\begin{array}{r}1.3981 E-03 \\
-1.1418 E-02 \\
10345 E-02 \\
7.0028 E-02 \\
-1.6773 E-01\end{array}$ & $\begin{array}{r}1.1101 E-02 \\
2.5249 E-02 \\
4.1609 E-02 \\
-1.3200 E-02 \\
0.8552 E-02\end{array}$ & $\begin{array}{r}9.2886 E-03 \\
-1.4326 E-03 \\
1.241 E-03 \\
1.0561 E-03 \\
1.3364 E-02\end{array}$ \\
\hline $\begin{array}{l}0.000 \\
0.000 \\
0.000 \\
0.000 \\
0.000\end{array}$ & $\begin{array}{c}0.000 \\
1.4616 E-01 \\
0.000 \\
6.0545 E-02 \\
-7.5102 E-02\end{array}$ & $\begin{array}{c}1.4537 E-01 \\
-2.6065 E-01 \\
3.5533 E-02 \\
-1.7297 E-01 \\
1.7771 E-01\end{array}$ & $\begin{array}{r}-1.1900 E-01 \\
1.3339 E-01 \\
-5.7603 E-02 \\
1.1630 E-01 \\
-1.8432 E .01\end{array}$ & $\begin{array}{l}4.2751 E-\infty 2 \\
1.3650 E-02 \\
1.6872 E-02 \\
6.4127 E-03 \\
9.9198 E-02\end{array}$ \\
\hline $\begin{array}{l}0.000 \\
0.000 \\
0.000 \\
0.000 \\
0.000\end{array}$ & $\begin{array}{c}0.000 \\
0.000 \\
0.000 \\
1.0377 E-01 \\
3.6483 E-01\end{array}$ & $\begin{array}{r}2.9373 E-01 \\
29850 E-01 \\
1.1619 E-01 \\
-1.5415 E-01 \\
.7 .0004 E-01\end{array}$ & $\begin{array}{r}-3.0166 E-01 \\
-3.6238 E-01 \\
-1.4109 E-01 \\
-5.9433 E-03 \\
3.0632 E-01\end{array}$ & $\begin{array}{l}1 \text { 124AE-01 } \\
1.3334 E-01 \\
8.2007 E-02 \\
8.2778 E-02 \\
52717 E-02\end{array}$ \\
\hline $\begin{array}{l}0.000 \\
0.000 \\
0.000 \\
0.000 \\
0.000\end{array}$ & $\begin{array}{c}1.3650 E+\infty 0 \\
0.000 \\
0.000 \\
0.000 \\
3.4001 E-01\end{array}$ & $\begin{array}{c}20129 E+00 \\
4 \text { SLE2E-01 } \\
15595 E-01 \\
80769 E-02 \\
-6.0599 E-01\end{array}$ & $\begin{array}{l}15722 E-01 \\
6.4045 E-01 \\
-1.8912 E-01 \\
1.9509 E-01 \\
1.3909 E-01\end{array}$ & $\begin{array}{l}5.2417 E-02 \\
2.4803 E-01 \\
1.0346 E-01 \\
1.5183 E-01 \\
1.6501 E-01\end{array}$ \\
\hline
\end{tabular}

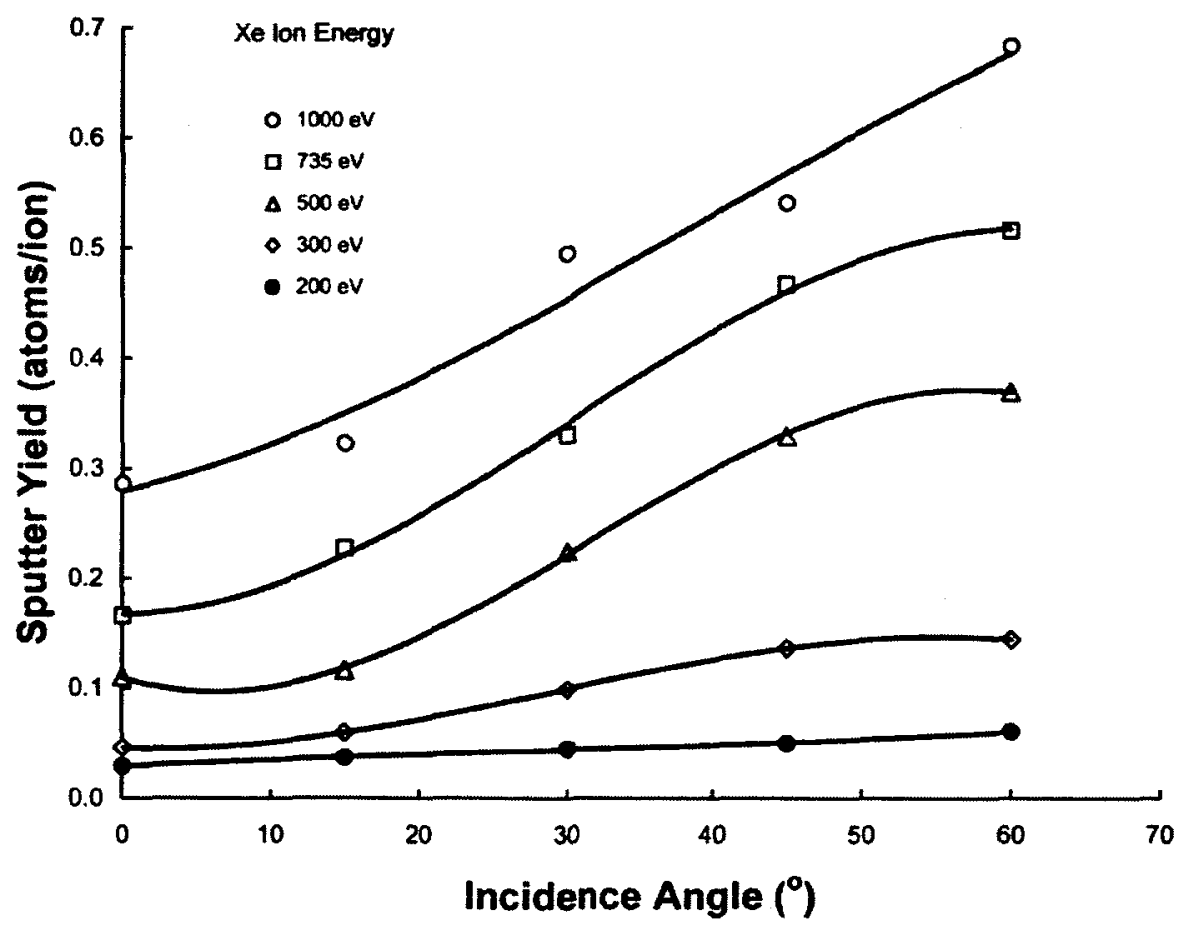

Fig. $22 \mathrm{CC}$ total sputter yield behavior as a function of incidence angle and ion energy. 


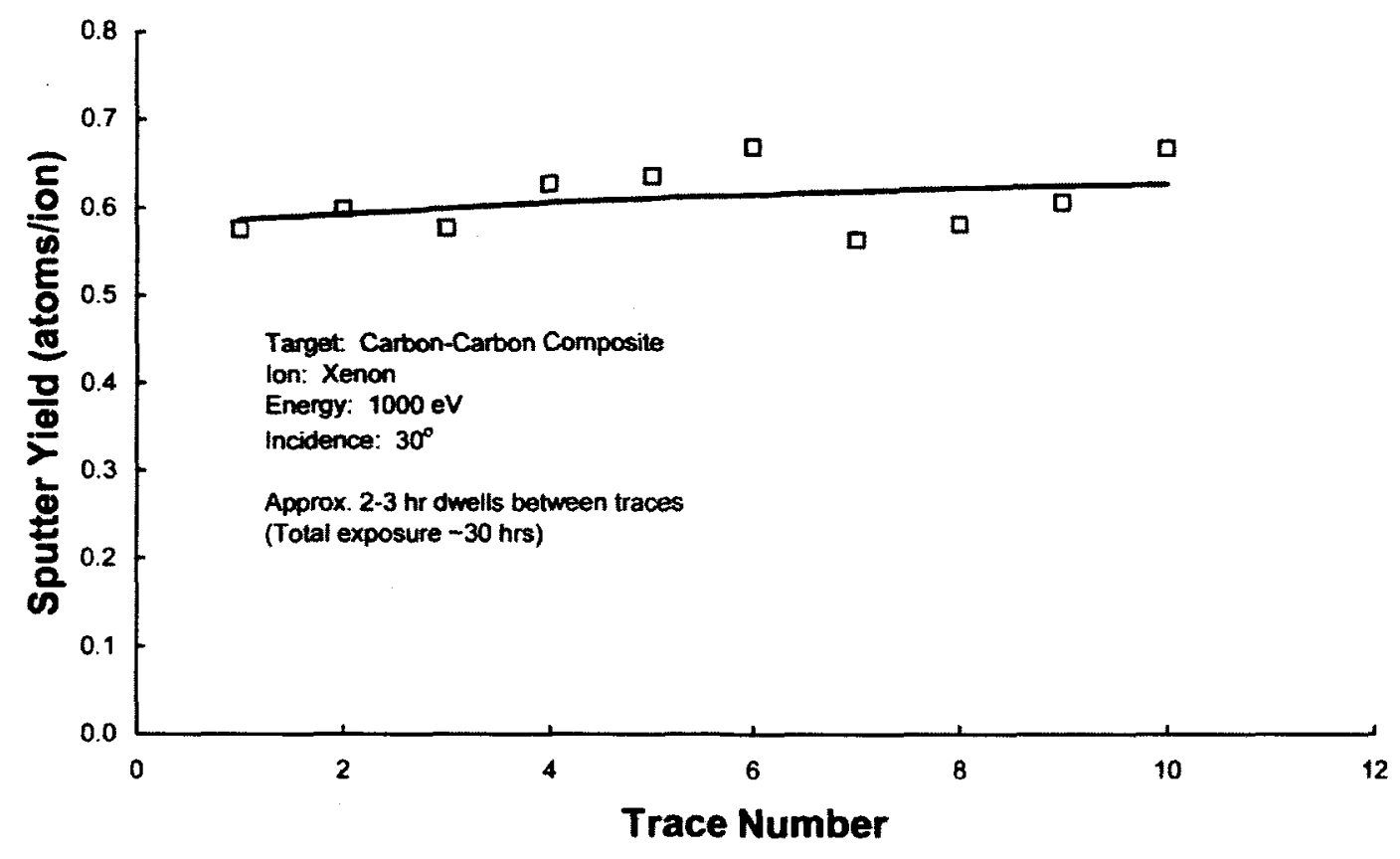

Fig. 23 Temporal dependence of total sputter yield of $\mathrm{CC}$ at a xenon ion energy of $1000 \mathrm{eV}$ and $30^{\circ}$ incidence.

\section{Comparison to Literature}

Figure 24 shows xenon sputter data obtained by Rosenberg and Wehner [1962], Deltschew et al. [2001], Williams et al. [2003], and Doerner et al. [2003] on polycrystalline graphite targets at normal incidence. The sputter yield data for graphite are in surprisingly good agreement with one another, and the lower ion energy data of Doerner et al. appear to be in about the right location below the other studies if a line were to be drawn through the various data sets. Predictions from an empirical model of Yamamura and Tawara [1996] are also shown in Fig. 24 for xenon sputtering of carbon, and it appears that the threshold energy of $161 \mathrm{eV}$ used in the empirical model may be too high to accurately predict the sputtering behavior of graphite at low energies. The PG and CC sputter yield data are observed to fall $\sim 40 \%$ below the experimentally measured sputter yield of graphite. It is pointed out that xenon ion sputter yield data collected by Deltschew et al. [2001] on carbon-carbon composite material were found to be significantly higher than graphite. However, in contrast to the current study, the composite material characterized by Deltschew et al. [2001] was not infiltrated with carbon or pyrolytically coated, and, consequently, the carbon fibers were directly exposed to the ion beam. Deltschew concluded that ions striking the cylindrical fiber surfaces at various incidence angles caused the sputter yield to be higher than graphite. 


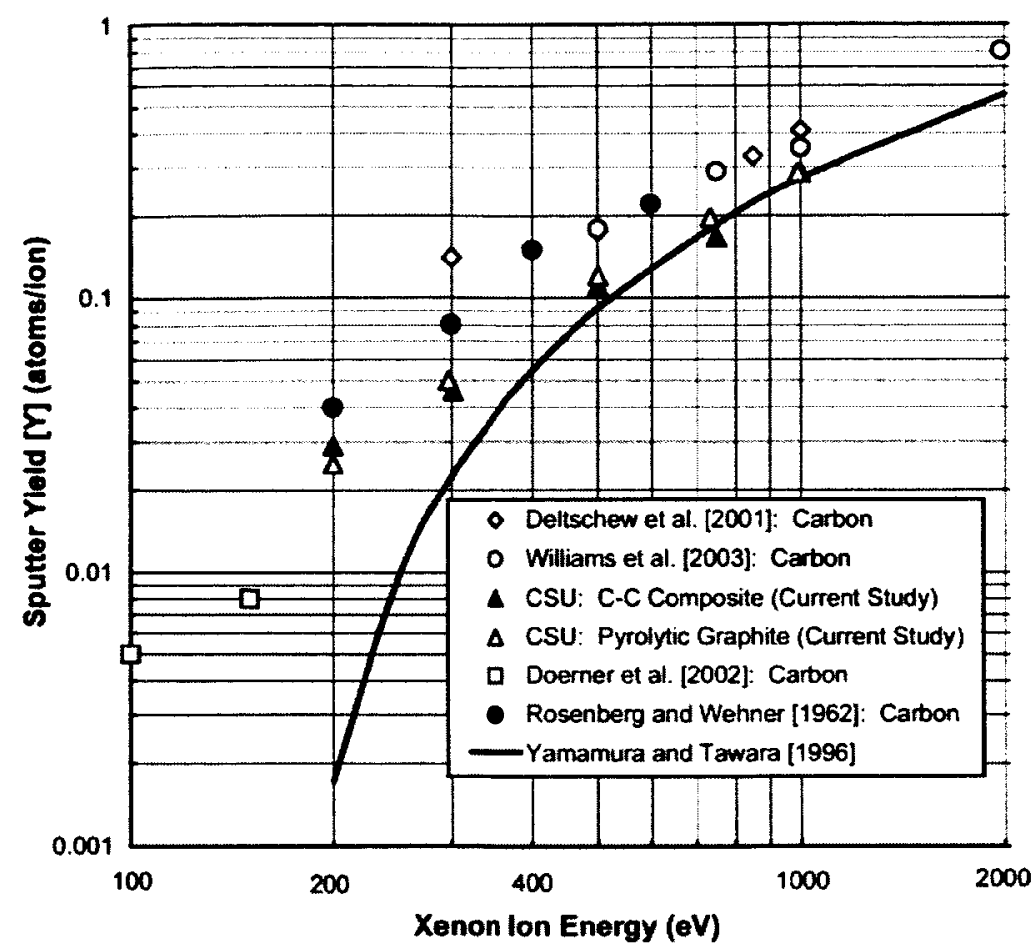

Fig. 24 Comparison of normal sputter yield data for xenon bombardment of different forms of carbon.

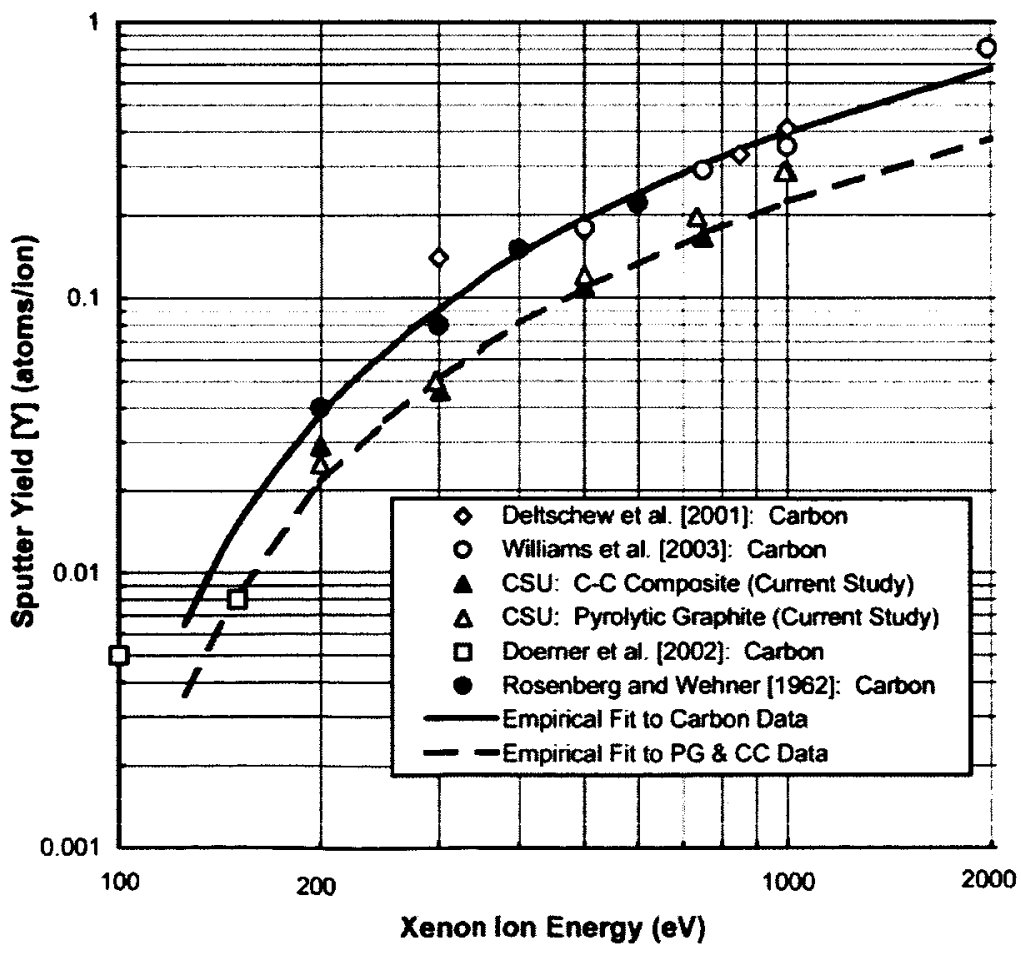

Fig. 25 New curve fits to sputter yield data for graphite, CC, and PG. 
The data presented in this paper allows one to determine the benefit of carbon-based ion optics systems over conventional ion optics fabricated from molybdenum (i.e., the additional propellant throughput that would be possible). To do this rigorously, the differential sputter yield data obtained in this program would need to be incorporated into a numerical model of an ion optics system that was able to calculate charge exchange ion generation rates and determine charge exchange ion trajectories and their subsequent energy and incidence angle as they strike the accel grid surface. However, the relative benefit of carbon over molybdenum can be estimated to first order by comparing the recession rates of surfaces being subjected to ion bombardment at normal incidence only. The rate of recession of a surface under normal incidence ion bombardment can be expressed as

$$
\mathbf{t}^{\prime}=\frac{\mathrm{m} \mathrm{Y} \mathrm{j}}{\mathrm{q} \rho}
$$

In Eq. (10), $m$ represents the mass of a target atom, $Y$ the total sputter yield, $j$ the current density of bombarding ions, and $\rho$ the density of the target.

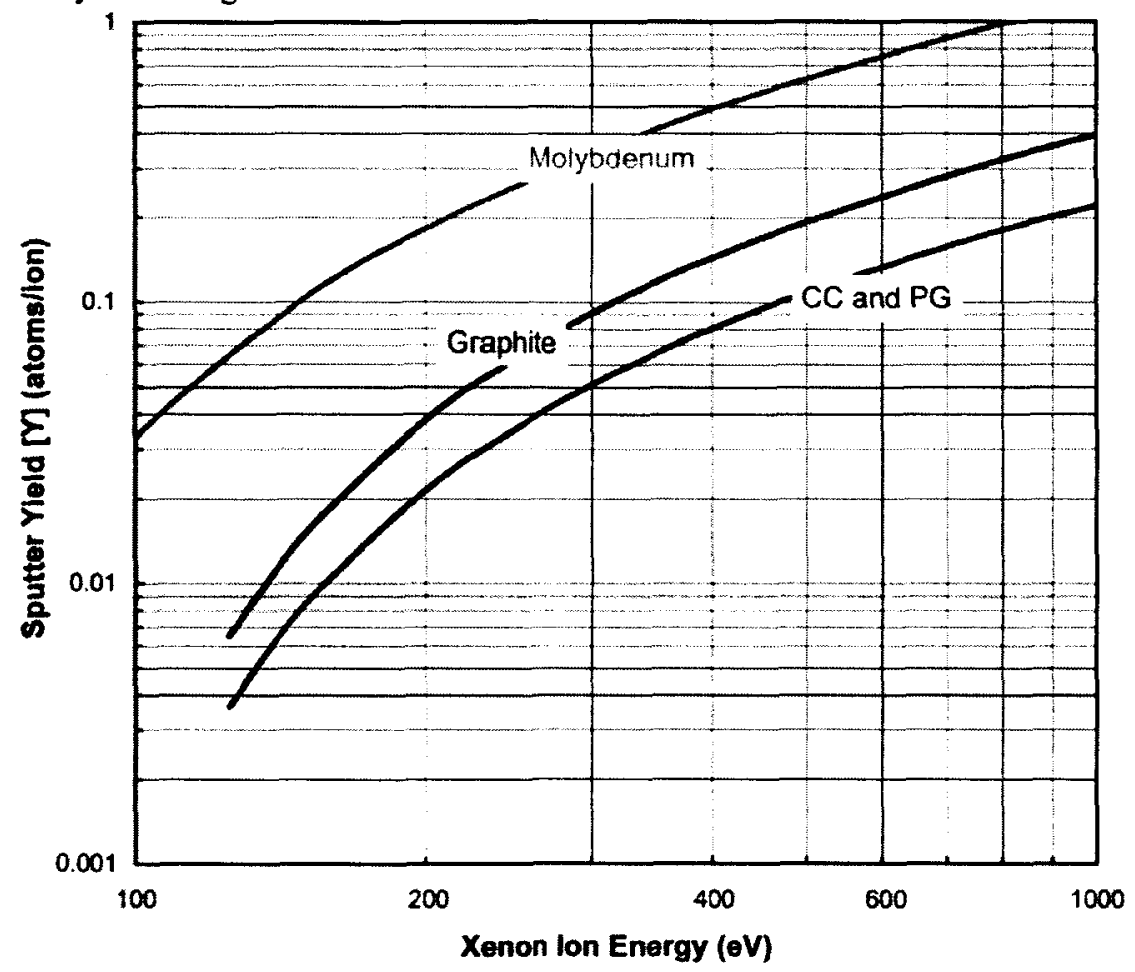

Fig. 26 Comparison of molybdenum, graphite, and CC-PG sputter yields at normal incidence.

The ratio of the recession rate of carbon to molybdenum is

$$
\frac{\mathrm{t}_{\mathrm{C}}^{\prime}}{\mathrm{t}_{\mathrm{Mo}}^{\prime}}=\frac{\mathrm{m}_{\mathrm{C}} \mathrm{Y}_{\mathrm{C}} \rho_{\mathrm{Mo}}}{\mathrm{m}_{\mathrm{Mo}} \mathrm{Y}_{\mathrm{Mo}} \rho_{\mathrm{C}}}=\left[\beta_{\mathrm{C}-\mathrm{Mo}}\right]^{-1}
$$

In Eq. (11) the subscripts $\mathrm{C}$ and Mo represent carbon (or graphite) and molybdenum and the parameter $\beta$ represents the propellant throughput performance relative to molybdenum. To first order, a grid set constructed of carbon that is subjected to normal incidence ion bombardment would have $\beta$ times more propellant throughput capability compared to molybdenum. Plots of $\beta$ for carbon (or graphite), pyrolytic graphite, carbon-carbon composite, and titanium are shown in Fig. 26. For xenon ion energies between $300 \mathrm{eV}$ and $1000 \mathrm{eV}$, grids fabricated from graphite would be expected to last 5 to 6.5 times longer than moly grids, and PG or CC grids would last 8 to 9.5 times longer. The curve for titanium grids shown in Fig. 26 suggests that this material would only be equivalent or slightly better than molybdenum in terms of propellant throughput over the entire $200 \mathrm{eV}$ to $1000 \mathrm{eV}$ range shown. It is noted that 
significant improvements in propellant throughput would be expected for carbon-based ion optics systems if the bombarding ion energy could be held to $250 \mathrm{eV}$ and lower.

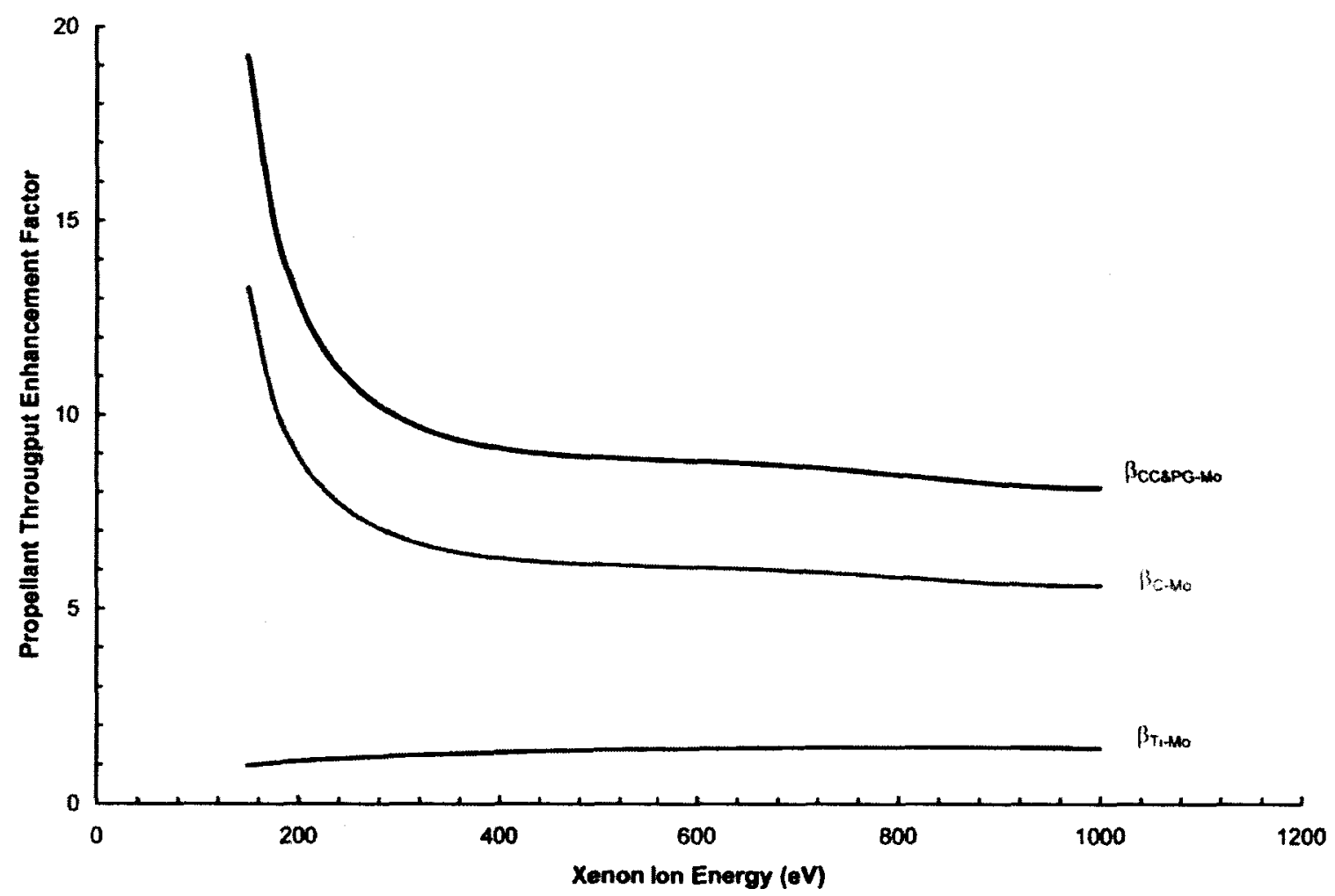

Fig. 27 Propellant throughput factors for graphite, PG, CC, and Ti grids relative to Mo grids.

\section{Conclusions}

Differential and total sputter yield measurements were presented for xenon ion bombardment of pyrolytic graphite (PG) and carbon-carbon (CC) composite materials. Both the ion energy and incidence angle were varied during this study over ranges from $200 \mathrm{eV}$ to $1000 \mathrm{eV}$ and normal incidence $\left(0^{\circ}\right)$ to $60^{\circ}$. Data collected at an incident angle of $5^{\circ}$ showed that differential sputter yields for pyrolytic graphite are extremely sensitive to incident angle and great care has been taken to align the ion beam and target normal directions. A high perveance grid assembly with small screen and accel grid holes $\left(d_{s}=0.95 \mathrm{~mm}\right.$ and $\left.d_{a}=0.64 \mathrm{~mm}\right)$ and small screen grid-to-accel grid spacing $\left(\ell_{\mathrm{g}} \sim 0.20 \mathrm{~mm}\right)$ was manufactured to enable testing at xenon ion energies of 200 and $300 \mathrm{eV}$. An important finding in this study was that the carbon-carbon composite sample displayed differential and total sputtering yield behavior that was nearly identical to the pyrolytic graphite sample. This result implies that the PVD infiltrated and pyro-coated carbon-carbon composite material should behave in a way that is similar to pyrolytic graphite in terms of erosion due to xenon ion bombardment. Furthermore, the total sputter yields of pyrolytic graphite and carbon-carbon composite at normal incidence were $40 \%$ less than values measured for electronic grade graphite (Poco AFX-5Q). Temporal experiments were completed in which the pyrolytic graphite and carboncarbon composite samples were subjected to the same sputtering conditions over many hours while periodic measurements were made of the differential sputter yield profile. Very little change in the differential sputter yield profile was detected over testing periods of $\mathbf{3 0}$ hours for either sample. This result suggests that the sputtering characteristics of the samples provided do not change considerably under ion bombardment even though tens of microns of material were removed during testing. 


\section{Acknowledgments}

Results of this work were generated under the NASA Marshall Space Flight Center (MSFC) In-Space Propulsion Technology Office with direction from Mr. Randy Baggett, Technical Area Manager of NASA MSFC Next Generation Electric Propulsion Technology Area. Financial support from Boeing Electron Dynamic Devices is gratefully acknowledged.

Behrisch and Wittmaack [1991]

\section{References and Bibliography}

R. Behrisch and K. Wittmaack, Sputtering by Particle Bombardment III, Springer-Verlag, Berlin, 1991.

Biersack and Eckstein [1984]

J.P. Biersack and W. Eckstein, "Sputtering Studies with the Monte Carlo Program TRIM.SP," Applied Physics A (Solids and Surfaces), V. 34, pp. 73-94, 1984.

Bohdansky et al. [1980]

J. Bohdansky, J. Roth, and H.L. Bay, "An Analytical Formula and Important Parameters for Low Energy Ion Sputtering," J. of Applied Physics, V. 51, No. 5, pp. 2861-2865, 1980.

Danailov et al. [2002]

D. Danailov, P. Keblinski, and D.J. O'Connor, "Effects of Terraces, Surface Steps, and "Over-Specular" Reflection Due to Inelastic Energy Losses on Angular Scattering Spectra for Glancing Incidence Scattering," Nuclear Instruments and Methods in Physics Research B, V. 193, pp. 544-549, 2002.

Deltschew et al. [2001]

R. Deltschew, M. Tartz, V. Plicht, E. Hartmann, H. Neumann, H.J. Leiter, and J. Esch, "Sputter Characteristics of Carbon-Carbon Compound Material," 27th International Electric Propulsion Conference, IEPC-01-118, Pasadena, CA, 2001.

De Pano et al. [2004]

M.K. De Pano, S.L. Hart, A.A. Hanna, and A.C. Schneider, "Fabrication and Vibration Results of 30-cm Pyrolytic Graphite Ion Optics," AIAA-2004-3615, 40 ${ }^{\text {th }}$ Joint Propulsion Conference, Ft. Lauderdale, FL, 2004.

Doerner et al. [2003]

R. P. Doerner, D. G. Whyte, and D. M. Goebel, "Sputtering Yield Measurements During Low Energy Xenon Plasma Bombardment," J. Applied Physics, V. 93, No. 9, pp. 5816-5823, 2003.

Eckstein [1991]

W. Eckstein, Computer Simulation of Ion-Solid Interactions, Springer-Verlag, Berlin, 1991.

Fine [1980]

J. Fine, "Absolute Sputtering Yield Measurement Methods: A Review," The Physics of Ionized Gases, Invited Lectures and Progress Reports of SPIC-80, M. Matic, ed., Beograd, 1980.

Gillen et al. [2002]

D.R. Gillen, W.G. Graham, and A. Goelich, "Sputtering of Copper Atoms by keV Atomic and Molecular Ions: A Comparison of Experiment with Analytical and Computer Based Models," Nuclear Instruments and Methods in Physics Research B, V. 194, pp. 409-416, 2002.

Goehlich et al. [2000]

A. Goehlich, N. Niemoller, and H.F. Dobele, "Anisotropy Effects in Physical Sputtering Investigated by LaserInduced Flourescence Spectroscopy,” Physical Review B, V. 62, N. 14, pp. 9349-9358, 2000.

Karolewski [2002]

M.A. Karolewski, "Classical Dynamics Simulations of Directional Effects in Sputtering from a Bimetallic Surface: $c(2 \times 2)-\mathrm{Pb} / \mathrm{Cu}(100)$," Nuclear Instruments and Methods in Physics Research B, V. 194, pp. 26-40, 2002.

Kosiba and Ecke [2002]

R. Kosiba and G. Ecke, "MC Simulations of Depth Profiling by Low Energy Ions," Nuclear Instruments and Methods in Physics Research B, V. 187, pp. 36-47, 2002.

Kustner et al. [1998]

M. Kustner, W. Eckstein, V. Dose, J. Roth, "The Influence of Surface Roughness on the Angular Dependence of the Sputter Yield," Nuclear Instruments and Methods in Physics Research B, V. 145, pp. 320-331, 1998.

Kustner et al. [1999]

M. Kustner, W. Eckstein, E. Hechtl, and J. Roth, "Angular Dependence of the Sputtering Yield of Rough Beryllium Surfaces," J. of Nuclear Materials, V. 265, pp. 22-27, 1999.

Mahan [2000] 
J. Mahan, Physical Vapor Deposition of Thin Films, John Wiley and Sons, Inc., New York, New York, 2000. Mantenieks et al. [2001]

M.A. Mantenieks, J.E. Foster, P.K. Ray, S.V. Shutthanandan, and T.S. Thevuthasan, "Low Energy Xenon Ion Sputtering Yield Measurements," 27th International Electric Propulsion Conference, IEPC-01-309, Pasadena, CA, 2001.

Marton and Fine [1990]

D. Marton and J. Fine, "Sputtering-Induced Surface Roughness of Metallic Thin Films," Thin Solid Films, V. 185 , pp. 79-90, 1990.

Oechsner [1973]

H. Oechsner, "Sputtering of Polycrystalline Metal Surfaces at Oblique Ion Bombardment in the $1 \mathrm{keV}$ Range,"

Z. Physik, V. 261, pp. 37-58., 1973.

Rosenberg and Wehner [1962]

D. Rosenberg and G.K. Wehner, "Sputtering Yields for Low Energy $\mathrm{He}+, \mathrm{Kr}^{+}$, and $\mathrm{Xe}+$ Ion Bombardment," J. of Applied Physics, V. 33, No. 5, pp. 1842-1845, 1962.

Shulga [2002]

V.I. Shulga, "Density Effects in Sputtering at Normal and Oblique Ion Bombardment," Nuclear Instruments and Methods in Physics Research B, V. 187, pp. 178-188, 2002.

Shutthanandan et al. [1997]

V. Shutthanandan, P.K. Ray, N.R. Shivaparan, R.J. Smith, S. Thevuthansan, and M.A. Mantenieks, "On the Measurement of Low Energy Sputtering Yield Using Rutherford Backscattering Spectrometry," $25^{\text {th }}$ International Electric Propulsion Conference, IEPC-97-069, Cleveland, OH, 1997.

Snyder et al. [2003]

J.S. Snyder, J.R. Brophy, D.M.Goebel, J.S. Beatty, and M.K. DePano, "Development and Testing of CarbonBased Ion Optics for 30-cm Ion Thrusters," $39^{\text {th }}$ Joint Propulsion Conference, AIAA-2003- 4716, Huntsville, $\mathrm{AL}, 2003$.

Stepanova and Dew [2001]

M. Stepanova and S.K. Dew, "Estimates of Differential Sputtering Yields for Deposition Applications," J. of Vacuum Science and Technology A, V. 19, No. 6, pp. 2805-2816, 2001.

Stepanova and Dew [2002A]

M. Stepanova and S.K. Dew, "Discrete-Path Transport Theory of Physical Sputtering," J. of Applied Physics, V. 92, No. 3, pp. 1699-1708, 2002.

Stepanova and Dew [2002B]

M. Stepanova and S.K. Dew, "Sputtering from lon-Beam-Roughened Cu Surfaces," Physical Review B, V. 66, 125407, 2002.

Stuart and Wehner [1964]

R.V. Stuart and G.K. Wehner, "Energy Distribution of Sputtered Cu Atoms," J. of Applied Physics, V. 35, No.

6, pp. 1819-1824, 1964.

Stuart et al. [1969]

R.V. Stuart, G. K. Wehner, and G.S. Anderson, "Energy Distribution of Atoms Sputtered from Polycrystalline Metals," J. of Applied Physics, V. 40, No. 2, pp. 803-812, 1969.

Wehner [1959]

G.K. Wehner, "Influence of the Angle of Incidence on Sputtering Yields," J. of Applied Physics, V. 30, No. 11, pp. 1762-1765, 1959.

Wehner and Rosenberg [1960]

G.K. Wehner and D. Rosenberg, "Angular Distribution of Sputtered Material," J. of Applied Physics, V. 31, No. 1, pp. 177-179, 1960.

Williams et al. [2003]

J.D. Williams, M.M. Gardner, M.L. Johnson, and P.J. Wilbur, "Xenon Sputter Yield Measurements for Ion Thruster Materials," $28^{\text {th }}$ International Electric Propulsion Conference, IEPC-03-130, Toulouse, France, 2003.

Yamamura et al. [1983]

Y. Yamamura, Y. Itikawa, and I. Noriaki. "'Angular Dependence of Sputtering Yields of Monatomic Solids," Institute of Plasma Physics, Report No. IPPJ-AM-26, Nagoya University, pp. 1-113, June 1983.

Yamamura and Tawara [1996]

Y. Yamamura and H. Tawara, "Energy Dependence of Ion-Induced Sputtering Yields from Monatomic Solids at Normal Incidence," Atomic Data and Nuclear Data Tables, Vol. 62, No. 2, pp. 149-254. 1996. 